\title{
An Overlooked Cost for the Velvety Plumage of Owls: Entanglement in Adhesive Vegetation
}

Author(s) :Airam Rodríguez, Felipe Siverio, Rubén Barone, Beneharo Rodríguez, and Juan J. Negro

Source: The Wilson Journal of Ornithology, 121(2):439-441. 2009.

Published By: The Wilson Ornithological Society

DOI: $10.1676 / 08-086.1$

URL: http://www.bioone.org/doi/full/10.1676/08-086.1

BioOne (www.bioone.org) is a nonprofit, online aggregation of core research in the biological, ecological, and environmental sciences. BioOne provides a sustainable online platform for over 170 journals and books published by nonprofit societies, associations, museums, institutions, and presses.

Your use of this PDF, the BioOne Web site, and all posted and associated content indicates your acceptance of BioOne's Terms of Use, available at www.bioone.org/page/terms_of_use.

Usage of BioOne content is strictly limited to personal, educational, and non-commercial use. Commercial inquiries or rights and permissions requests should be directed to the individual publisher as copyright holder. 


\title{
Short Communications
}

The Wilson Journal of Ornithology 121(2):406-411, 2009

\section{American Robin Seet Calls: Aerial Alarm or a Contact Call?}

\author{
E. Natasha Vanderhoff ${ }^{1,2,3}$ and Perri K. Eason ${ }^{1}$
}

\begin{abstract}
The literature regarding the seet call of the American Robin (Turdus migratorius) is unclear as anecdotal accounts indicate it is an aerial alarm. A more recent, comprehensive account indicates it is most likely a contact call. We examined the meaning of seet calls through observations and a playback experiment, both of which support the aerial alarm function of the call. Robins only gave seet calls to aerial predators and many engaged in skygazing, a behavior previously unreported for robins. Robins engaged in three anti-predator behaviors, skygazing, alert, and scanning for significantly more time after hearing an alarm compared to hearing a control. American Robins, like many other birds, probably evolved this call to avoid detection by aerial predators and to warn conspecifics. Received 14 July 2008. Accepted 14 December 2008.
\end{abstract}

Birds use a variety of calls to communicate and can readily comprehend and discriminate between calls in their repertoire. However, it often takes years for scientists to fully understand the context and meaning of many calls. The study of avian communication has evolved from largely observational accounts to hypothesis-driven experimentation, often with aid of technology, which has allowed scientists to discern the meaning of many birds' calls (Baptista and Gaunt 1994). Alarm calls may be particularly important communications, as they may allow birds to warn conspecifics and escape predation, and potentially have an immediate effect on fitness (Klump and Shalter 1984). Many birds have alarm calls and, in some species, different kinds of alarms are given for different types of threats (Marler 2004). Some species give distinctive alarms for ground and aerial predators, a refinement that allows conspecifics to gain much more information from the alarm and

\footnotetext{
${ }^{1}$ Department of Biology, University of Louisville, Louisville, KY 40299, USA.

${ }^{2}$ Current address: Francis Marion University, P. O. Box 100547, Florence, SC 29501, USA.

${ }^{3}$ Corresponding author; e-mail: evanderhoff@fmarion.edu
}

respond appropriately for a specific kind of threat (Evans et al. 1993, Evans 2002). For example, Steller's Jay (Cyanocitta stelleri) give a wah call when mobbing ground predators and a high-pitched call when hawks are seen (Hope 1980), both of which elicit a different response. We investigated whether the American Robin (Turdus migratorius) has a distinctive aerial alarm call given for aerial predators and examined conspecifics' response to that call.

Previous research on robin alarm calls focused on those given in response to terrestrial predators, and these calls have been clearly characterized (Shedd 1982, Gottfried et al. 1985). Robins give two types of terrestrial alarm calls, yeeps and chucks. However, robins also have numerous aerial predators with accipiters (Cooper's Hawk [Accipiter cooperii] and Sharp-shinned Hawk [A. striatus]) being particularly important predators (Roth and Lima 2003, Roth et al. 2006) and, accordingly, an aerial alarm might provide a strong selective advantage. Currently there are conflicting reports in the literature concerning whether or not robins have an aerial alarm. Two anecdotal reports from the 1950's suggested that robins give a seet call in the presence of aerial predators and that robins become "rigid" when they hear that call (Jackson 1952, Hailman 1959). The seet call is higher pitched and longer in duration than other alarm calls in the robin's repertoire (Fig. 1) and it sounds similar to the call of Cedar Waxwings (Bombycilla cedrorum); robins often have bouts of seet calls, during which they repeatedly give this vocalization. Two later studies assumed the robin seet call was an aerial alarm and used it in investigations of hawks' perception of alarm calls (Brown 1982, Jones and Hill 2001). A recent review of robin behavior and ecology by Sallabanks and James (1999) suggested this call might be used as a contact call between males and females, and between par- 


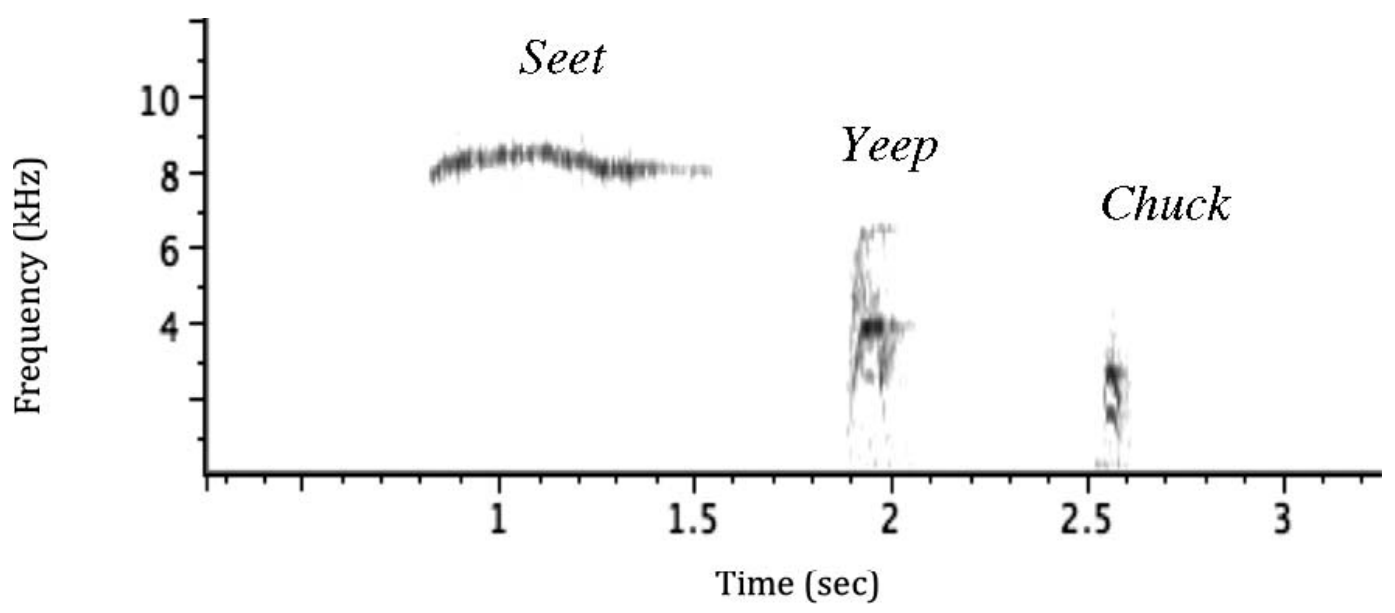

FIG. 1. Spectrogram of American Robin alarm calls.

ents and young; however, they did not mention its possible use as an aerial alarm.

Our goal was to clarify the meaning of the American Robin seet call and conspecifics' responses to the call. We first examined the context of the call, recording whether we could see a terrestrial or aerial predator when a robin gave seet calls, and then recorded the calls for description and analysis. We also noted the behavior of conspecifics in response to the calls. Finally, we compared the responses of robins to recorded calls and a control of white-noise in a playback experiment.

\section{METHODS}

We conducted our study from 25 May to 25 November 2006 at two public parks in Louisville, Kentucky: Joe Creason Park (27.5 ha; $\left.38^{\circ} 12^{\prime} \mathrm{N}, 85^{\circ} 42^{\prime} \mathrm{W}\right)$ and George Rogers Clark Park (18.6 ha; $38^{\circ} 12^{\prime} \mathrm{N}, 85^{\circ} 42^{\prime} \mathrm{W}$ ). Both parks contain forested patches and open grassy areas with scattered trees. We recorded six bouts of seet calls during spring 2006 using a Sennheiser ME 62 directional microphone connected to a Sony TCM-5000 EV recorder. Recordings were made within $3 \mathrm{~m}$ of the vocalizing robin and, in all instances, a raptor (Accipiter spp.) was seen in the area immediately prior to or during recording. We analyzed these calls using Raven bioacoustic software (Cornell Laboratory of Ornithology 2003) and recorded the following: length of the calling bout, number of calls within a bout, inter-call interval, and call rate (number of calls/min). We also calculated the average duration, and minimum and maximum frequencies of a single seet call.

We collected data on the occurrences of seet calls on 31 days between 26 May and 21 September 2006 to test if seet calls were given solely in the presence of aerial predators. We noted when we heard a seet call and recorded whether we observed a raptor or terrestrial predator when the alarm was given. We compared the proportion of calls given in the presence of aerial predators versus terrestrial predators with Chi-square. We also noted during this observational study when robins displayed one anti-predator behavior not previously reported in this species, skygazing. Skygazing behavior was defined by the following postural change: robin froze, squatted low to the ground with its neck bent towards its back and beak pointing skyward. Individuals hearing seet calls as well as individuals giving seet calls displayed this behavior.

We conducted a short playback experiment in which we played recorded seet calls to 10 adult robins and a control (white noise) to an additional 10 adult robins while they were foraging on the ground. We performed these playbacks only when no terrestrial or aerial predators were visible in the area and when no robins had been giving any alarm calls for at least $30 \mathrm{~min}$. The seet call playback consisted of three seet calls played over $15 \mathrm{sec}$, which represented a short bout and a conservative test of robins' responsiveness to this 


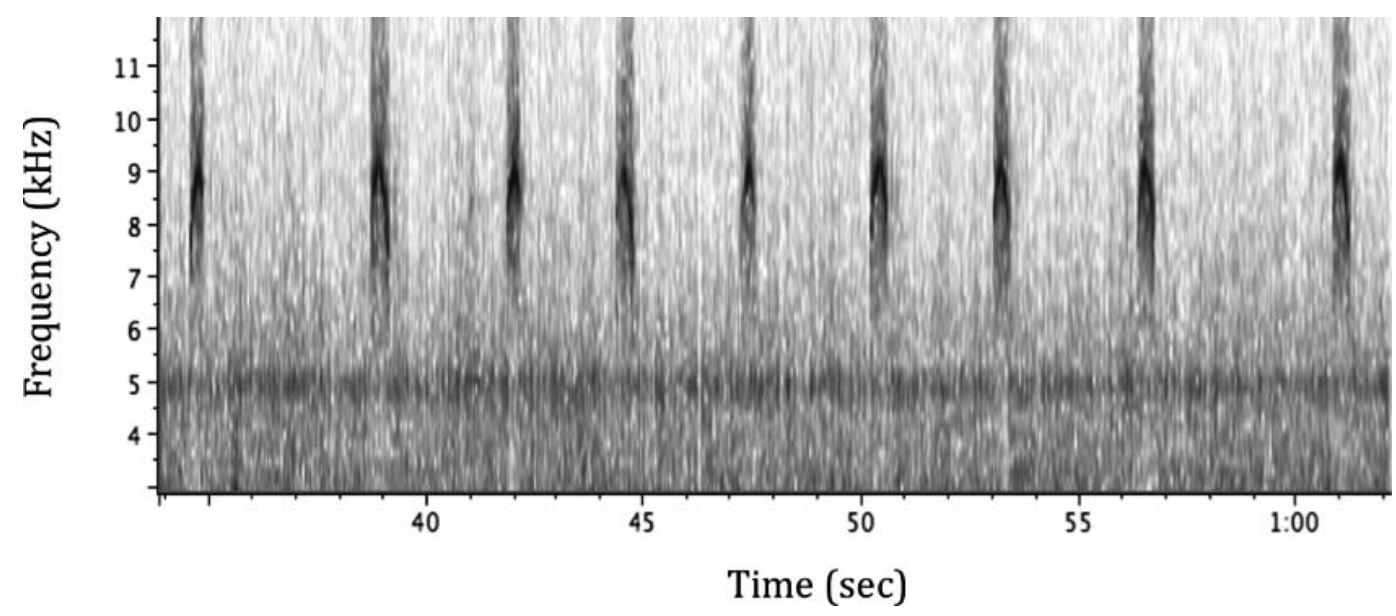

FIG. 2. Spectrogram of American Robin seet call bout.

call. We also recorded white-noise, broad band noise at a constant frequency, for $15 \mathrm{sec}$ as a control. We observed robins for $2 \mathrm{~min}$ after playing either white noise or the seet calls. We noted whether or not the focal bird stopped foraging during these observations and whether the bird performed any of three anti-predator behaviors. These behaviors included standing alert, scanning, and skygazing. Robins standing alert froze in an erect position; scanning birds also stood in place but turned their heads rapidly from left to right, appearing to scan the area. We performed a Chi-square test to compare the proportion of robins that stopped foraging after hearing a seet call versus after hearing whitenoise. We used MANOVA to compare the robins' behaviors after playbacks between the two treatments. SAS (SAS Institute Inc. 2003) was used for all statistical tests and data are reported as means $\pm \mathrm{SE}$.

\section{RESULTS}

The call bouts of American Robins giving seets lasted on average $186 \pm 49.9 \mathrm{sec}$ (range 23-315), and the average number of calls given within a bout was $38.8 \pm 12.3$. The interval between calls was $5.5 \pm 1.1 \mathrm{sec}$ (range 1-33) and, on average, robins gave $11.4 \pm 2.9$ seet calls/min. Individual seet calls lasted $<1 \mathrm{sec}$ $(0.424 \pm 0.010, n=130)$ and had a minimum frequency of $7306.6 \pm 38.5 \mathrm{~Hz}$ and a maximum frequency of $9012.3 \pm 67.6 \mathrm{~Hz}(n=$ 130; Fig. 2).
We heard robin seet calls on 29 of $31 \mathrm{ob}-$ servation days. We observed solitary robins and those in flocks emitting seet calls. However, on most occasions we observed calling birds after the initial vocalizations and were unable to tell if the bird was alone at the time the alarm was initially given. We saw an aerial predator (accipiter hawk) on 16 of the 29 occasions. There were many terrestrial predators at the parks where we conducted our study, but we did not hear robins give the seet call in response to any terrestrial predator $\left(\chi^{2}=\right.$ 22.0952, $P<0$. 0001). We also saw robins skygazing in the vicinity of a robin delivering a seet call on 16 of the 29 days. This behavior was not observed in response to terrestrial predators or the terrestrial alarm calls, yeeps and chucks.

The behavior of robins hearing white-noise in the playback experiments differed strongly from that of robins hearing seet calls. No robins stopped foraging after a playback of whitenoise; in contrast, all robins stopped foraging when they heard the seet call $\left(\chi^{2}=20.0, P<\right.$ $0.0001)$. Most robins stopped foraging almost immediately upon hearing the call; the average time between hearing the call and stopping foraging was $2.6 \pm 0.8 \mathrm{sec}$, and values for this lag time ranged from 1 to $8 \mathrm{sec}$. Robins often engaged in one of the three antipredator behaviors we recorded; $90 \%$ scanned the sky, $80 \%$ stood alert, and $50 \%$ engaged in skygazing. Robins hearing playbacks of seet calls engaged in these behaviors for signifi- 


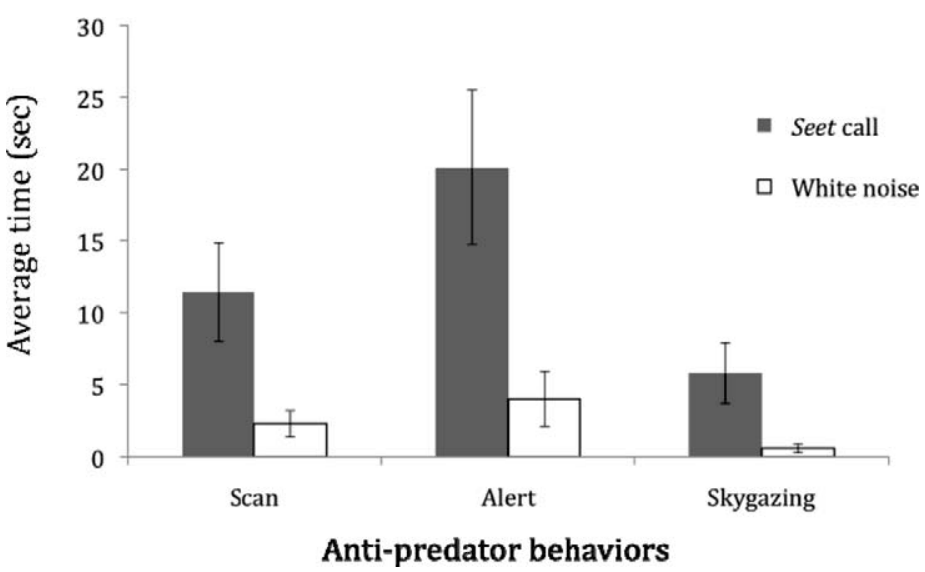

FIG. 3. American Robins spend significantly more time scanning (ANOVA, $F_{1,18}=6.14, P=0.0234$ ), alert (ANOVA, $F_{1,18}=7.12, P=0.0156$ ), and skygazing (ANOVA, $F_{1,18}=5.51, P=0.0306$ ) after hearing a playback of a seet call as compared to white- noise.

cantly more time than did individuals hearing white-noise (Wilk's Lamba $F_{3,16}=8.14, P=$ 0.0016; Fig. 3).

\section{DISCUSSION}

Our investigation supports the early observational accounts reporting the American Robin seet call is an aerial alarm. Seet calls were only given in response to aerial predators, and robins altered their behavior upon hearing playbacks of the call. They also engaged in a novel anti-predator behavior, skygazing, which presumably allows the robin to scan the sky for danger. A more appropriate test of the function of skygazing would be to compare behaviors after hearing all three call types, seets, yeeps, and chucks. We did not test this function of skygazing, but preliminary results from playbacks of chuck calls (not reported here) and observational data support our findings that skygazing occurs only in response to seet calls. Future work should be conducted to understand the exact conditions that elicit this behavioral response, i.e., whether robins skygaze more or less often when the risk of predation is higher.

The bouts we recorded lasted $\sim 3 \mathrm{~min}$ on average, but we often heard robins giving seet calls for longer durations. Several robins in different areas of the park could be heard giving seet calls for extended periods of time, $>30 \mathrm{~min}$ on one occasion. It was difficult to discern if robins in one area called after hearing a robin calling in another area of the park; however, no robin gave a seet call after hearing the seet playback. It is easy to see how these calls might have been classified as contact calls, especially considering that an aerial predator is often not visible when robins are calling. An accipiter was only visible to us in our observations on about half of the days we heard robins engaging in seet call bouts, most likely because we failed to see the raptor as it flew between patches of trees.

Numerous birds have developed highpitched alarm calls in response to aerial predators including Wood Thrush (Hylocichla mustelina) (Saunders 1961), Tufted Titmouse (Baelophus bicolor) (Morse 1970), Bank Swallow (Riparia riparia) (Windsor and Emlem 1974), Black-capped Chickadee (Poecile atricapillus) (Ficken and Witkin 1977), and Rufous-backed Robin (Turdus rufopalliatus) (Grabowski 1979). High-pitched calls, like robin seet calls, are difficult for predators to localize (Marler 1955, 2004; Brown 1982; Jones and Hill 2001). It is likely these calls evolved as warnings for birds other than the predator, unlike the robin's other mobbing calls (Shedd 1982, Gottfried et al. 1985). Two generally recognized explanations for evolution of warning calls are reciprocal altruism and kin selection (Klump and Shalter 1984). The cost of giving a call must be low relative to the benefit gained by receivers for reciprocal altruism to evolve, and signalers must have a high probability of encountering one 
another repeatedly (Trivers 1971, Axelrod and Hamilton 1981). Seet calls likely have a relatively low cost for the signaler given they can not be easily distinguished by predators. Seet calls may therefore fit the criteria for evolution through reciprocal altruism. Seet calls may have also evolved through kin selection.

Our study was conducted after the breeding season, during a time when juveniles were independent from their parents. The relatedness of individuals in a foraging flock is unknown for robins (Sallabanks and James 1999); however, it is likely that some flock mates may be related, leading to benefits for kin when an individual gives alarm calls. Another possibility to explain evolution of seet calls in robins is that the confusing nature of the calls acts to increase an individual's direct fitness, i.e., emitting seet calls directly deters predators by minimizing their ability to locate and capture the individual emitting the call.

Our data do not allow us to discriminate among these mechanisms, but they are testable. If alarms are given when robins are foraging alone, it would suggest the calls have direct fitness benefits. If calls are only emitted in flocks, it is likely they evolved, at least in part, to warn kin or other conspecifics. It would be necessary to track whether robins emit these calls more often in the presence of dependent young than in their absence to discriminate between these two possibilities. Testing these predictions will lead to a better understanding of how these important signals evolved in the American Robin.

\section{ACKNOWLEDGMENTS}

We thank Louisville Metro Parks for allowing us to conduct our study at Joe Creason and George Rogers Clark parks. We also thank Catherine Byers, Chadwick Hanna, Tom Pelletier, and anonymous reviewers for helpful comments on the manuscript. This investigation was funded by a small grant to ENV from the University of Louisville, Biology Graduate Student Organization.

\section{LITERATURE CITED}

Axelrod, R. And W. D. Hamilton. 1981. The evolution of cooperation. Science 211:1390-1396.

Baptista, L. F. And S. L. L. Gaunt. 1994. Advances in studies of avian sound communication. Condor 96:817-830

Brown, C. H. 1982. Ventroloquial and locating vocal- izations in birds. Zeitschrift Tierpsychologia 59: 338-350.

Cornell Laboratory of Ornithology. 2003. Raven Pro 1.3 Bioacoustic Software. Cornell University, Ithaca, New York, USA.

Evans, C. S. 2002. Cracking the code: communication and cognition in birds. Pages 315-322 in The cognitive animal (M. Bekoff, C. Allen, and G. M. Burghardt, Editors). MIT Press, Cambridge, Massachusetts, USA.

Evans, C. S., L. Evans, And P. Marler. 1993. On the meaning of alarm calls: functional reference in an avian vocal system. Animal Behaviour 46:23-38.

FICKEN, M. S. AND S. R. WITKIN. 1977. Responses of Black-capped Chickadee flocks to predators. Auk 94:156-157.

Gottfried, B. M., K. Andrews, and M. Haug. 1985. Breeding robins and nest predators: effect of predator type and defense strategy on initial vocalization patterns. Wilson Bulletin 97:183-190.

Grabowski, G. L. 1979. Vocalizations of the Rufousbacked Thrush (Turdus rufopalliatus) in Guerrero, Mexico. Condor 81:409-416.

Hailman, J. P. 1959. An avian predator alarm of the American Robin. Journal of Field Ornithology 30: 46-47.

Hope, S. 1980. Call form in relation to function in the Steller's Jay. American Naturalist 116:788-820.

JACKSON, M. 1952. A warning call of the American Robin, Turdus migratorius. Auk 69:466.

Jones, K. J. AND W. L. Hill. 2001. Auditory perception of hawks and owls for passerine alarm calls. Ethology 107:717-726.

Klump, G. M. And M. D. Shalter. 1984. Acoustic behaviour of birds and mammals in the predator context. Zeitschrift Tierpsychologia 66:189-226.

MARLER, P. 1955. Characteristics of some animal calls. Nature 176:6-8.

MARler, P. 2004. Bird calls: a cornucopia for communication. Pages 132-177 in Nature's music, the science of birdsong (P. Marler and H Slabbekoorn, Editors). Elsevier Academic Press, London, United Kingdom.

Morse, D. H. 1970. Ecological aspects of some mixedspecies foraging flocks of birds. Ecological Monographs 40:119-168.

Roth II, T. C. AND S. L. LiMA. 2003. Hunting behavior and the diet of Cooper's Hawk: an urban view of the small-bird-in-winter paradigm. Condor 105: 474-483.

Roth II, T. C., S. L. Lima, And W. E. Vetter. 2006. Determinants of predation risk in small wintering birds: the hawk's perspective. Behavioral Ecology and Sociobiology 60:195-204.

Sallabanks, R. And F. C. JAMES. 1999. American robin (Turdus migratorius). The birds of North America. Number 462.

SAS InstituTE InC. 2003. SAS system Version 9.1 for Windows. SAS Institute Inc., Cary, North Carolina, USA. 
Saunders, A. A. 1961. The songs and calls of the Wood Thrush. Auk 78:595-606.

SHEDD, D. H. 1982. Seasonal variation and function of mobbing and related antipredator behaviors of the American Robin (Turdus migratorius). Auk 99: 342-346.
TRIVERS, R. L. 1971. The evolution of reciprocal altruism. Quarterly Review of Biology 46:35-57.

WindsoR, D. AND S. T. EMLEM. 1975. Predator-prey interactions of adult and prefledgling Bank Swallows and American Kestrels. Condor 77:359361 .

\title{
Habitat Selection of Least Flycatchers Includes Deciduous Regeneration in Pine Plantations
}

\author{
Andrea M. Geboers ${ }^{1,2}$ and Erica $\mathrm{Nol}^{1}$
}

\begin{abstract}
Least Flycatchers (Empidonax minimus) are socially monogamous birds that exhibit clustered nesting behavior. We examined the potential influence of forest structure in habitat selection, and formation of Least Flycatcher clusters within a habitat type not previously studied in this species: red pine (Pinus resinosa) plantations. We documented 10\% less understory vegetation, $13 \%$ greater canopy cover, and $30 \%$ more deciduous trees in occupied than in adjacent, unoccupied, yet available habitat in 12 clusters in pine plantations. Well developed canopy cover and deciduous foliage appear to provide visual cues for Least Flycatchers when selecting habitat for breeding. Received 3 July 2008. Accepted 10 December 2008.
\end{abstract}

Studies of clustered nest patterns in birds have focused on both ecological and social factors that might promote this apparent sociality (Ward and Schlossberg 2004, Tarof et al. 2005, Ahlering et al. 2006). Conspecific attraction is a social behavior that may influence settlement patterns whereby individuals are attracted to the presence of other individuals of the same species and subsequently establish adjacent territories (Stamps 1988). Conspecific attraction may be a cue to (perceived) habitat quality (VanHorne 1983); however, preference for a particular habitat may also be cued by vegetation structure (Hildén 1965, Sherry and Holmes 1985).

Clustered nesting in all-purpose territories has been observed in at least five species of

\footnotetext{
${ }^{1}$ Biology Department, Trent University, Peterborough, ON K9J 7B8, Canada.

${ }^{2}$ Corresponding author; e-mail: andreageboers@trentu.ca
}

North American songbirds: Yellow Warbler (Dendroica petechia; Clark and Robertson 1979), Henslow's Sparrow (Ammodramus henslowii; Cully and Michaels 2000), Loggerhead Shrike (Lanius ludovicianus; Etterson 2003), Baird's Sparrow (Ammodramus bairdii; Ahlering et al. 2006), and Cerulean Warbler (Dendroica cerulea; Roth and Islam 2007). Clustered breeding may occur in some species for competitive exclusion, predator defense, use of patchy resources, or from social factors including increased potential for extra-pair copulations (reviewed in Tarof and Ratcliffe 2004). These hypotheses have been examined with mixed results to explain clustered nesting behavior of Least Flycatchers (Empidonax minimus) (Sherry and Holmes 1985, Perry and Andersen 2003, Tarof and Ratcliffe 2004, Tarof et al. 2005).

Least Flycatcher clusters occur within a patch of apparently homogeneous forest habitat while other areas within the same patch are left unoccupied (Breckenridge 1956, Perry and Andersen 2003). All previously reported studies involving clustering behavior of Least Flycatchers have been conducted in predominately deciduous forests. Our objective in this study was to identify breeding habitat characteristics of Least Flycatchers in red pine (Pinus resinosa) plantations. Studying different habitat types used by Least Flycatchers may further our understanding of habitat selection and links to clustering behavior in this species.

\section{METHODS}

Study Area.-We studied Least Flycatchers at Ganaraska Forest $\left(44^{\circ} 5^{\prime} \mathrm{N}, 78^{\circ} 30^{\prime} \mathrm{W}\right) 30$ 
$\mathrm{km}$ south of Peterborough, Ontario, Canada (hereafter, the Forest) from late May to midJuly 2007. The Forest is a 4,280-ha tract comprised of $\sim 50 \%$ pine plantation and $50 \%$ mixed hardwoods in contiguous patches. Pine plantations are predominately red pine. The mixed hardwood forests are predominately sugar maple (Acer saccharum), American beech (Fagus grandifolia), red oak (Quercus rubra), and white birch (Betula papyrifera). The red pine plantation stands are 25 to 70 years of age and have been managed using row thinning and subsequent selective thinning every 10-15 years (S. McMullen, Ganaraska Region Conservation Authority, pers. comm.), which promotes the growth of deciduous trees. The predominant sapling species are red oak and black cherry (Prunus seroti$n a$ ), and ground cover is largely poison ivy (Toxicodendron radicans). The terrain is generally undulating to hilly and is underlain by glacial-fluvial deposits, primarily of sand or sandy-loam texture (Tedford 1978).

Mapping Clusters.-Observations were made in areas within the Forest where Least Flycatchers were nesting. We chose 12 red pine plantations in which to map clusters based on presence of two or more calling males within $\sim 75 \mathrm{~m}$ of conspecifics. Conservative estimates indicate 12 clusters were occupied by 2-7 territorial males with a mean density of 3.6 males/ha. Delineation of cluster boundaries was conducted between 25 and 30 June from 0600 to 1100 hrs EDT. We walked the perimeter of the cluster from an arbitrary starting point within each chosen area of known Least Flycatcher location. We stopped every $50 \mathrm{~m}$ to perform a 2-min point count survey to listen for calling males and to record the location using a Global Positioning System (GPS) (Garmin GPS 12, Garmin International Inc., Olathe, KS, USA.). The Least Flycatcher has a distinctive song, chebec, which males sing frequently during the breeding period, up to $60 \mathrm{times} / \mathrm{min}$ (MacQueen 1950) making them easy to distinguish and locate. GPS locations were plotted and connected to form polygons.

Habitat Characteristic Measurements.-We compared forest vegetation characteristics in occupied areas (inside clusters, $n=12$ ) with adjacent unoccupied, but available areas within the same plantation forest patch (outside clusters, $n=12$ ). A $5 \times 10 \mathrm{~m}$ rectangular plot was established centrally within occupied areas. All vegetation plots in unoccupied areas were $>50 \mathrm{~m}$ from the delineated cluster boundary to preclude any possibility of cluster boundary discrepancy. Vegetation plots between 50 and $100 \mathrm{~m}$ from cluster boundaries should represent unused, but available habitat (Jones 2001) because all feeding and nesting occur within their respective territories (i.e., all-purpose territories).

Vegetation characteristics sampled in occupied and unoccupied areas included percent living ground cover, bare soil, stone, leaf litter, and coarse woody debris (CWD). Vertical layers, based on height and diameter at breast height (dbh) $(1.2 \mathrm{~m})$ categories, were estimated using percent cover, regeneration (0.5-1.3 $\mathrm{m}$ tall and $<2.5 \mathrm{~cm} \mathrm{dbh})$, saplings $(>1.3 \mathrm{~m}$ in height and $<2.5 \mathrm{~cm} \mathrm{dbh})$, understory $(>2.5 \mathrm{~m}$ tall and $\geq 2.5$ but $<8 \mathrm{~cm} \mathrm{dbh}$ ), and sub-canopy (10-20 $\mathrm{m}$ tall and $\geq 8 \mathrm{~cm} \mathrm{dbh).} \mathrm{Canopy} \mathrm{cover} \mathrm{was} \mathrm{mea-}$ sured using a Model-C densiometer (Lemmon 1956). The tallest tree in each plot was measured with a clinometer (Korning and Thomsen 1994), and basal area was estimated using a factor-2 prism sweep (Arsenault et al. 2006). All trees ( $\geq 8 \mathrm{~cm} \mathrm{dbh}$ ) and saplings, dead or alive, within each plot were identified to species.

Statistical Analysis.-Tests for normality and homogeneity of variance were performed on the data. Square-root or arcsine were used when data did not meet these assumptions. All tests were performed using an alpha of 0.05 .

We compared habitat characteristics between occupied and unoccupied areas using Student's $t$-test for all variables except number of trees where the unequal variance $t$-test was used because, even with transformation, this variable was not normally distributed. Bonferroni corrections were not used to minimize the probability of Type II error (Moran 2003).

Tree ( $\geq 8 \mathrm{~cm} \mathrm{dbh}$ ) species counts were combined into two groups: coniferous (including red pine, white pine [Pinus strobus]), and deciduous (black cherry, red oak, white oak [Quercus alba], white birch, American beech, and sugar maple), and compared between occupied and unoccupied areas using a twotailed Fisher's exact test. Means and \pm SE are presented as untransformed values. All statistical analyses were performed with STATISTICA $^{\text {(III) }}$ (Version 7.0; StatSoft Inc. 2004). 


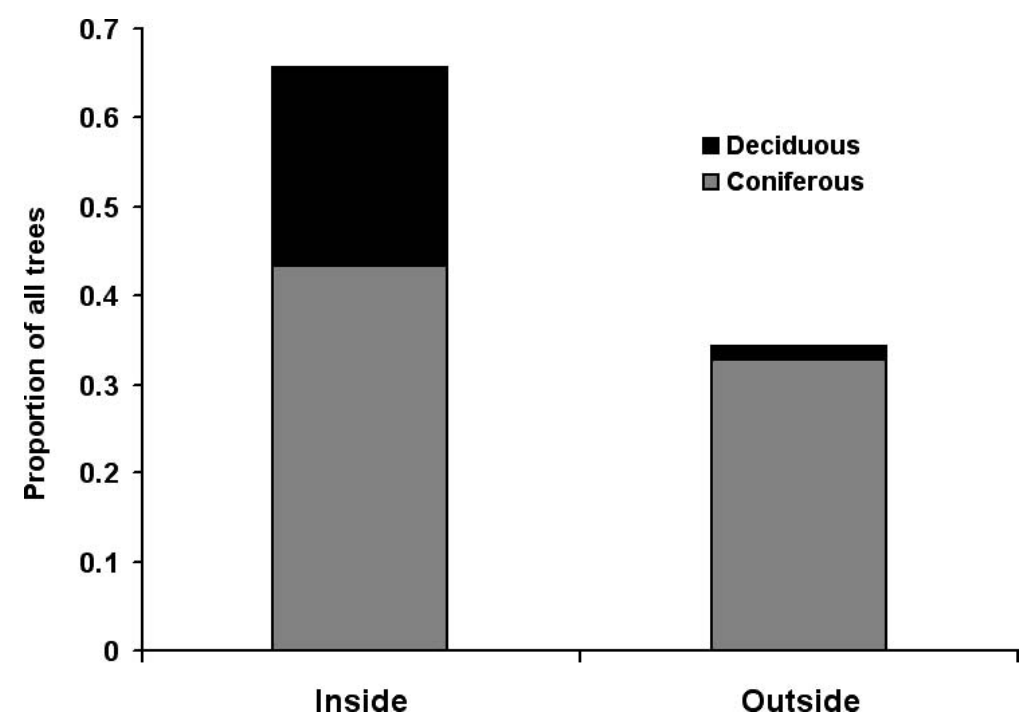

FIG. 1. The proportion of all trees (deciduous and coniferous) inside and outside Least Flycatcher clusters in south-central Ontario red pine plantations, 2007. Sample size $=12$ vegetation plots both inside and outside of clusters.

\section{RESULTS}

Occupied areas (inside clusters) had more, $15 / 44(34 \%)$, deciduous trees $(\geq 8 \mathrm{~cm} \mathrm{dbh})$ than unoccupied areas (outside the clusters) where only $1 / 23(4 \%)$ were deciduous (Fisher's exact test, $P=0.007$; Fig. 1). Canopy cover and number of trees $\geq 8 \mathrm{~cm}$ dbh were significantly greater inside versus outside the clusters (Table 1). The amount of understory vegetation was marginally significant with greater mean understory cover outside than inside clusters.

\section{DISCUSSION}

We report the first use of pine plantations by Least Flycatchers for nesting. Our study suggests that regenerating deciduous trees, as a result of tree thinning operations, attract Least Flycatchers. More deciduous and total number of trees inside Least Flycatcher clusters resulted in greater canopy cover than in red pine plantation sites adjacent and outside these clusters. The greater canopy cover suppressed growth of understory vegetation inside the clusters. Other studies also report

TABLE 1. Habitat variables inside and outside Least Flycatcher clusters in red pine plantations in southcentral Ontario, 2007. Statistical significance was ascertained using a $t$-test for all variables. All sample sizes include 12 clusters and 12 areas outside clusters.

\begin{tabular}{|c|c|c|c|}
\hline & Inside clusters & Outside clusters & \\
\hline Vegetation variable & Mean $\pm \mathrm{SE}$ & Mean $\pm \mathrm{SE}$ & $P$ \\
\hline Live ground cover, $\%$ & $36.3 \pm 6.7$ & $44.8 \pm 6.2$ & 0.358 \\
\hline Leaf litter, \% & $44.0 \pm 6.9$ & $40.8 \pm 6.2$ & 0.732 \\
\hline Coarse wood debris, $\%$ & $9.3 \pm 1.5$ & $9.4 \pm 2.7$ & 0.967 \\
\hline Regeneration cover, \% & $6.3 \pm 1.5$ & $20.1 \pm 7.4$ & 0.086 \\
\hline Sapling cover, $\%$ & $8.2 \pm 1.5$ & $8.5 \pm 3.1$ & 0.912 \\
\hline Understory cover, \% & $8.2 \pm 3.6$ & $18.8 \pm 3.6$ & 0.052 \\
\hline Sub-canopy cover, $\%$ & $32.9 \pm 8.6$ & $37.9 \pm 5.9$ & 0.637 \\
\hline Canopy cover, $\%$ & $84.2 \pm 2.8$ & $71.3 \pm 5.3$ & 0.042 \\
\hline Basal area, $\mathrm{m}^{2} / \mathrm{ha}$ & $21.3 \pm 1.1$ & $20.3 \pm 1.9$ & 0.853 \\
\hline Tallest tree, $\mathrm{m}$ & $21.1 \pm 1.0$ & $21.8 \pm 1.0$ & 0.640 \\
\hline Mean number of trees/plot & $3.7 \pm 0.7$ & $1.9 \pm 0.2$ & 0.046 \\
\hline
\end{tabular}


Least Flycatcher occupancy was associated with a well-developed canopy (DellaSala and Rabe 1987, Darveau et al. 1992, Perry and Andersen 2003) and a relatively open understory (Breckenridge 1956, Johnston 1971, Sherry and Holmes 1985). Certain structural and compositional features of a forest, such as a minimum required canopy cover, appear to provide visual cues in Least Flycatcher habitat selection.

Clustering was not associated with differences in forest structure in other studies examining the habitat hypothesis (Sherry and Holmes 1985, Tarof and Ratcliffe 2004). This does not imply that habitat selection cues based on structure of vegetation are not used by Least Flycatchers when choosing where to settle. The predominately deciduous forests in these studies may have a homogeneous, welldeveloped canopy cover which flycatchers may use to form clusters without apparent preference for habitat features within these forests. Relatively dense canopy cover including deciduous foliage may be important for Least Flycatcher foraging. Least Flycatchers use a hovering tactic to glean prey from foliage and may need an open sub-canopy to detect prey movements in the denser main canopy (Robinson and Holmes 1982). Rogers (1985) reported Least Flycatchers use deciduous foliage for foraging more than Pinus spp. when compared to the proportion of tree species available.

Habitat selection has fitness consequences and high quality habitats are preferred to increase fitness (Johnson 2007). Cues used as indicators of high quality habitat may include vegetation (Hildén 1965), presence of conspecifics (Stamps 1988, Ward and Schlossberg 2004), or both. Several studies have found that Least Flycatchers respond to song of conspecifics during settlement (Mills et al. 2006, Fletcher 2007), but the first individual to arrive and begin singing in an appropriate habitat must be cued by something other than conspecific attraction (Roth and Islam 2007, but see Betts et al. 2008). Least Flycatchers may be stimulated to settle in habitats, including red pine plantations, with a relatively closed canopy due to presence of deciduous trees. This may be a basic, yet essential, component of Least Flycatcher habitat defining the innate cue used by the first males arriving and establishing territories. However, a full deciduous canopy may not provide an explanation for clustered breeding.

Several alternate hypotheses for aggregating behavior in Least Flycatchers have been proposed. Clustering during breeding may have (1) a predator deterrence effect through mobbing and alarm calls (Perry and Andersen 2003), (2) a means of competitive exclusion of American Redstarts (Setophaga ruticilla) (Sherry and Holmes 1988), or (3) may be in response to female pursuit of extra-pair copulations and formation of hidden leks (Tarof et al. 2005). No study has reported conclusive and consistent results to explain clustering, but most studies have found some evidence related to these hypotheses. Least Flycatchers may benefit in several ways from clustering behavior; each benefit may be acting synergistically to promote and/or maintain the behavior. Our study suggests a necessary precursor to formation of Least Flycatcher clusters is a deciduous habitat component.

\section{ACKNOWLEDGMENTS}

We are grateful to the Oak Ridges Moraine Foundation and Environment Canada for funding this project. Our appreciation is also expressed to Brendan Hickie for valuable comments, and to Paul Woodward, Donna Tozzi, Myles Falconer, and Ben Walters for field assistance.

\section{LITERATURE CITED}

Arsenault, E. J., R. J. Hall, R. S. Skakun, E. H. Hogg, and M. Michaelian. 2006. Pages 1-6 in Characterizing aspen dieback severity using multidate landsat data in western Canadian forests. Eleventh Forest Service Remote Sensing Applications Conference, Salt Lake City, Utah, USA.

Ahlering, M. A., D. H. Johnson, AND J. FAABorg. 2006. Conspecific attraction in a grassland bird, the Baird's Sparrow. Journal of Field Ornithology 77:365-371.

Betts, M. G., A. S. Hadley, N. Rodenhouse, and J. J. NoCERA. 2008. Social information trumps vegetation structure in breeding-site selection by a migrant songbird. Proceedings of the Royal Society of London Series B 275:2257-2263.

BRECKENRIDGE, W. J. 1956. Measurements of the habitat niche of the Least Flycatcher. Wilson Bulletin 68:47-51.

Clark, K. L. and R. J. Robertson. 1979. Spatial and temporal multi-species nesting aggregations in birds as anti-parasite and anti-predator defenses. Behavioral Ecology and Sociobiology 5:359-371.

Cully, J. F. AND H. L. Michaels. 2000. Henslow's 
Sparrow habitat associations on Kansas tallgrass prairie. Wilson Bulletin 112:115-123.

Darveau, M., J. L. DesGranges, and G. Gauthier. 1992. Habitat use by three breeding insectivorous birds in declining maple forests. Condor 94:72-82.

DellaSala, D. A. and D. L. Rabe. 1987. Response of Least Flycatchers Empidonax minimus to forest disturbances. Biological Conservation 41:291299.

EtTerson, M. A. 2003. Conspecific attraction in Loggerhead Shrikes: implications for habitat conservation and reintroduction. Biological Conservation 114:119-205.

FleTCHER, R. J. 2007. Species interactions and population density mediate the use of social cues for habitat selection. Journal of Animal Ecology 76: 598-606.

HiLdÉN, O. 1965. Habitat selection in birds. Annales Zoologici Fennici 2:53-75.

Johnson, M. D. 2007. Measuring habitat quality: a review. Condor 109:489-504.

Johnston, D. W. 1971. Niche relationships among some deciduous forest flycatchers. Auk 88:796804.

JONES, J. 2001. Habitat selection studies in avian ecology: a critical review. Auk 118:557-562.

Korning, J. AND K. Thomsen. 1994. A new method for measuring tree height in tropical rain forest Journal of Vegetation Science 5:139-140.

LEMMON, P. E. 1956. A spherical densiometer for estimating forest overstory density. Forest Science 2:314-320

MacQueEn, P. M. 1950. Territory and song in the Least Flycatcher. Wilson Bulletin 62:194-205.

Mills, A. M., J. D. Rising, AND D. A. JACKSON. 2006. Conspecific attraction during establishment of Least Flycatcher clusters. Journal of Field Ornithology 77:34-38.

Moran, M. D. 2003. Arguments for rejecting the sequential Bonferroni in ecological studies. Oikos 100:403-405.

Perry, E. F. AND D. E. Andersen. 2003. Advantages of clustered nesting for Least Flycatchers in northcentral Minnesota. Condor 105:756-770.
Robinson, S. K. AND R. T. Holmes. 1982. Foraging behavior of forest birds: the relationships among search tactics, diet, and habitat structure. Ecology 63:1918-1931.

Rogers, C. M. 1985. Foraging success and tree species use in the Least Flycatcher. Auk 102:613-620.

Roth, K. L. AND K. Islam. 2007. Do Cerulean Warblers (Dendroica cerulea) exhibit clustered territoriality? American Midland Naturalist 157:345355.

SHERry, T. W. AND R. T. Holmes. 1985. Dispersion patterns and habitat responses of birds in northern hardwoods forests. Pages 283-309 in Habitat selection in birds (M. L. Cody, Editor). Academic Press, San Diego, California, USA.

SHERry, T. W. AND R. T. Holmes. 1988. Habitat selection by breeding American Redstarts in response to a dominant competitor, the Least Flycatcher. Auk 105:350-364.

Stamps, J. A. 1988. Conspecific attraction and aggregation in territorial species. American Naturalist 131:329-347.

Statsoft InC. 2004. Statistica for Windows 7.0. Statsoft Inc., Tulsa, Oklahoma, USA.

TAROF, S. A. AND L. M. RATCLIFFE. 2004. Habitat characteristics and nest predation do not explain clustered breeding in Least Flycatchers (Empidonax minimus). Auk 121:877-893.

Tarof, S. A., L. M. Ratcliffe, M. M. Kasumovic, AND P. T. BoAG. 2005. Are Least Flycatcher (Empidonax minimus) clusters hidden leks? Behavioral Ecology 16:207-217.

Tedford, J. A. 1978. Ganaraska Forest Study. Ganaraska Region Conservation Authority. Ontario Ministry of Natural Resources, Peterborough, Ontario, Canada.

VAnHoRne, B. 1983. Density as a misleading indicator of habitat quality. Journal of Wildlife Management 47:893-901.

Ward, M. P. AND S. SChLOSSBERG. 2004. Conspecific attraction and the conservation of territorial songbirds. Conservation Biology 18:519-525. 


\title{
Nocturnal Predation of Females on Nests: An Important Source of Mortality for Golden-cheeked Warblers?
}

\author{
Jennifer L. Reidy, ${ }^{1,5}$ Mike M. Stake, ${ }^{2,4}$ and Frank R. Thompson III ${ }^{3}$
}

\begin{abstract}
We monitored 124 female Goldencheeked Warblers (Dendroica chrysoparia) at 133 nests with video cameras from 1997-2002 and 20052006 at two study areas in central Texas, USA. Six adult females were depredated by snakes in 781 camera-monitored intervals when females were on the nest at night and exposed to possible nocturnal predation. Daily nest survival was 0.971 (95\% CI: 0.959-0.980) and daily adult female predation while nesting was 0.008 (95\% CI: $0.003-0.017)$. We estimated that $14.6 \%$ of breeding females were depredated on the nest during the breeding season based on the observed survival rates and assuming females whose first nest was unsuccessful and which survived attempted a second nesting attempt. Females were captured $75 \%$ of the times they were on the nest at the time of a nocturnal nest predation by a snake. Predation of nesting females is potentially an important source of mortality for Golden-cheeked Warblers, and warrants further investigation. Received 7 June 2008. Accepted 30 August 2008.
\end{abstract}

Survival of migrant songbirds is generally thought to be high during the breeding season (Sillett and Holmes 2002); however, there is little direct evidence of the frequency or sources of adult mortality during this period. Documenting any predation event on the nest is difficult (Pettingill 1976) and adult mortality is usually inferred from remains left at the nest (Sherry and Holmes 1997, Flaspohler et al. 2001). Often evidence suggests that adults were killed in defense of the nest or circumstantially, and were not the intended victim (Fendley 1980, Quinn 1985, King 1999). Interpretation of evidence at the nest, however,

\footnotetext{
${ }^{1}$ Department of Fisheries and Wildlife Sciences, University of Missouri, Columbia, MO 65211, USA.

${ }^{2}$ Division of Biological Sciences, University of Missouri, Columbia, MO 65211, USA.

${ }^{3}$ Northern Research Station, U.S. Forest Service, University of Missouri, Columbia, MO 65211, USA.

${ }^{4}$ Current address: Hawks Aloft, P. O. Box 10028, Albuquerque, NM 87184, USA.

${ }^{5}$ Corresponding author; e-mail: jennifer.reidy@gmail.com
}

can be an unreliable method to identify nest fate, cause of nest failure, or identity of a predator (Thompson et al. 1999).

Video surveillance has recently been shown to be an effective and reliable method to identify and evaluate the importance of nest predators (Thompson 2007). The main groups of nest predators identified from these studies were sciurids, corvids, raptors, and snakes. Adult mortality was only observed in two studies using video surveillance to monitor songbirds - a thirteen-lined ground squirrel (Spermophilus tridecemlineatus) depredated one Chestnut-collared Longspur (Calcarius ornatus) female (Pietz and Granfors 2000) and rat snakes (Elaphe spp.) depredated three Golden-cheeked Warbler (Dendroica chrysoparia) females (Stake et al. 2004). The potential for snake predation of incubating females has long been speculated (Laskey 1946, Mahan 1956), but this phenomenon has rarely been documented (Plummer 1977, Blem 1979, Carter 1992). We believe snakes pose the greatest risk of depredating adult songbirds at the nest because they are the only group known to be significant nocturnal predators, at least in some habitats (Hensley and Smith 1986, Stake and Cimprich 2003, Stake et al. 2004, Reidy et al. 2008), large enough to kill and consume adult songbirds.

We monitored Golden-cheeked Warbler nests with video cameras and report on causes and rates of nest mortality, and identity of nest predators elsewhere (Stake et al. 2004, Reidy et al. 2008). Our objective in this study is to report on the extent of adult mortality at the nest and discuss its potential implications. Golden-cheeked Warblers, a federally endangered species, are endemic breeders in central Texas with strict nesting habitat requirements (Ladd and Gass 1999). The requisite mixed mature Ashe juniper (Juniperus ashei) and oak (Quercus spp.) woodlands in which they nest are currently being heavily fragmented 
and developed in historically important parts of the breeding range (USDI 1992).

\section{METHODS}

Study Area.-We monitored nests of Golden-cheeked Warblers at Fort Hood Military Reservation, Texas, USA $\left(30^{\circ} 10^{\prime} \mathrm{N}, 97^{\circ} 45^{\prime}\right.$ W) from 1997 to 2002 and in 2005 , and in Austin, Texas $\left(30^{\circ} 23^{\prime} \mathrm{N}, 97^{\circ} 34^{\prime} \mathrm{W}\right)$ from 2005 to 2006. Fort Hood (Bell and Coryell counties) is a large, active military base in a rural landscape with discrete patches of Golden-cheeked Warbler habitat separated by open valleys leased for cattle grazing. Austin (Travis County) is a large and growing city with historically large amounts of contiguous breeding habitat currently being fragmented by human development.

Field Methods.-We mapped territories of banded and unbanded adults from March to May to establish pairing and nesting status of males, and to narrow the nest-searching area. We searched for nests from March to June, typically using adult behavioral cues to locate nests. We placed miniature video cameras with infra-red illumination (Fuhrman Diversified Inc., Seabrook, TX, USA) that allowed continuous monitoring at as many nests as possible during the incubation and nestling stages, prioritizing nests in the incubation stage. Video cameras were attached by a $20-\mathrm{m}$ long cable to a video recorder and battery placed as far from the nest as possible. We monitored nests daily using a monitor that plugged into the video recorder and did not approach the nest while it was active after the camera was installed. We recorded standard monitoring information daily including nest contents and identified nest predators to the lowest possible taxa when we concluded a predation event had occurred. We used banding and territory status, and nest success information to establish the number of females we monitored with video cameras (several females were monitored with video cameras during more than one nesting attempt). Additional monitoring details are available in Stake et al. (2004) and Reidy et al. (2008).

Data Analyses.-We estimated daily survival of nests with a logistic exposure model (Shaffer 2004) in SAS 9.1 (SAS Institute 2004). We coded survival as 1 if at least one egg or nestling in the nest survived the inter- val and as 0 if all nest contents were destroyed. We fit a model with covariates for date, date ${ }^{2}$, and date ${ }^{3}$ to account for potentially non-linear effects of date (Grant et al. 2005, Reidy 2007). We ignored other potential temporal covariates such as nest stage or year because there was not much support for them in previous analyses examining factors affecting Golden-cheeked Warbler nest survival (Stake 2003, Peak 2007, Reidy 2007). We estimated daily nest survival with the above model for median nest interval observed in the study (Shaffer and Thompson 2007).

We similarly estimated female daily survival with a logistic exposure model; we coded survival as 1 if the female survived the overnight observation interval and as 0 if she was depredated. We fit a constant survival (intercept only) model because there were too few mortality events to model as a function of covariates. We only included observations from the days females sleep on the nest because that is when they are potentially exposed to predation (nest days 3-21). We estimated female daily predation as 1 - daily survival.

We estimated total loss of adult females during the breeding season due to predation on the nest based on daily nest survival, daily female mortality, and number of nesting attempts. If daily nest survival is assumed constant, the proportion of nests surviving to any given day of the nest cycle can be estimated as $p_{k}=s^{k}$, where $p_{k}$ is the proportion of nests surviving to day $\mathrm{k}$ and $\mathrm{s}$ is the daily survival estimate. If the daily mortality of females on the nest is defined as $\mathrm{m}$ and is also assumed constant for nest days 3-21 (assuming the female begins incubating the penultimate egg of a typical 4-egg clutch, Pulich 1976), the proportion of females lost to predation during the first nest attempt is: $F_{1}=\Sigma_{k=3-21}\left(s^{k} \times m\right)$. If we assume females which were successful in their first nesting attempt do not re-nest and that all females whose first attempt failed and which survived re-nest, the proportion of females lost to predation during a second nesting attempt is: $F_{2}=\left(1-p^{25}-F_{1}\right) \times F_{1}$, where $\mathrm{p}^{25}$ is the proportion of females which were successful during their first attempt and $F_{1}$ is the proportion of females which died on their first attempt. The total proportion of nesting females dying due to predation on the nest, $\mathrm{F}_{\mathrm{T}}$, can be estimated as: $\mathrm{F}_{\mathrm{T}}=\mathrm{F}_{1}+\mathrm{F}_{2}$. 
TABLE 1. Video camera-monitored nests of Golden-cheeked Warblers at Fort Hood, Texas, USA from 1997 to 2002 and 2005, and in Austin, Texas, USA, in 2005 and 2006. Most years had $\geq 4$ nests with cameras during days 3-21 of the nest cycle and produced at least one snake predation of a female attending the nest.

\begin{tabular}{clccc}
\hline Year & \multicolumn{1}{c}{ Site } & $\begin{array}{c}\text { Number of nests } \\
\text { monitored with } \\
\text { cameras (total } \\
\text { observation days) }\end{array}$ & $\begin{array}{c}\text { Number of nests } \\
\text { monitored during } \\
\text { days 3-21 (total } \\
\text { observation days) }\end{array}$ & $\begin{array}{c}\text { Number of female } \\
\text { mortalities (number } \\
\text { of females } \\
\text { monitored) }\end{array}$ \\
\hline 1997 & Fort Hood & $1(13)$ & $1(10)$ & $0(1)$ \\
1998 & Fort Hood & $2(36)$ & $2(28)$ & $0(2)$ \\
1999 & Fort Hood & $2(21)$ & $2(16)$ & $0(2)$ \\
2000 & Fort Hood & $6(40)$ & $4(28)$ & $1(6)$ \\
2001 & Fort Hood & $30(292)$ & $26(198)$ & $0(29)$ \\
2002 & Fort Hood & $24(189)$ & $15(125)$ & $2(20)$ \\
2005 & Fort Hood & $7(68)$ & $6(32)$ & 0 \\
2005 & Austin & $18(174)$ & $13(100)$ & $17)$ \\
2006 & Austin & $43(364)$ & $31(244)$ & $2(16)$ \\
\hline
\end{tabular}

Females rarely made a third nesting attempt after two failures and we recorded no instances of double brooding (J. L. Reidy, pers. obs.).

\section{RESULTS}

We monitored 133 nests (61 in Austin and 72 on Fort Hood) representing 124 females with video cameras for an effective sample size of 1,197 nest monitoring intervals (Table 1). We recorded 43 nest predations on video; however, 11 of these were considered successful because $\geq 1$ host young fledged despite a nest predation event. Rat snakes were the leading predator at both sites, depredating 21 nests. Texas rat snakes (Elaphe obsoleta lindheimeri) and a Great Plains rat snake (E. guttata emoryi) depredated 20 and 1 nests, respectively. We recorded females being captured and consumed during six of these nest predations, three at each site. We identified Texas rat snakes as the predator at five adult predation events and a Great Plains rat snake at one.

Daily nest survival was 0.971 (95\% CI: 0.959-0.980). We observed six predations of females by snakes over 781 observation days during nest days 3-21, resulting in a daily female predation rate of 0.008 (95\% CI: $0.003-$ 0.017 ). We estimated 0.103 (or 10.3\%) of breeding females were depredated during their first nesting attempt. If all surviving females with failed nests re-nested (42\% of initial population), we estimated 0.043 (or 4.3\%) of breeding females were depredated during their second nesting attempt. Total losses of breeding females to predation amounted to $14.6 \%$.
If females spent one less or one more night at the nest (all else being equal), these totals would be 14.0 or $15.2 \%$, respectively.

All predations of females were nocturnal, occurring between 2103 and 2352 hrs CDT from 18 April to 9 May in Austin, and between 0022 and 0448 hrs from 23 April to 17 May at Fort Hood. All nest predations by snakes $(n=21)$ were nocturnal but one, occurring between 2001 and 2352 hrs from 18 April to 19 May in Austin and between 2037 and $0448 \mathrm{hrs}$ from 23 April to 10 June at Fort Hood. One additional nest predation by a snake occurred at $1024 \mathrm{hrs}$ at Fort Hood.

Snakes were not deterred by Goldencheeked Warblers nesting in the canopy. Nests with depredated females were on average 5.2 $\mathrm{m}(n=6$; range $=4.2$ to $6.1 \mathrm{~m})$ above ground and $1.8 \mathrm{~m}$ from the main trunk $(n=6$; range $=0.3$ to $4.5 \mathrm{~m}$ ) on trees with a diameter at breast height averaging $23 \mathrm{~cm}(n=6$; range $=12$ to $43 \mathrm{~cm}$ ). Nests were in Ashe junipers, which are characterized by rough, peeling bark.

Four of the total snake nest predations $(19 \%)$ were in the incubation stage and 17 $(81 \%)$ in the nestling stage. Two of four $(50 \%)$ snake nest predations during the incubation stage resulted in predation of the female. Of the remaining two, the female was present at one and left the nest 3 min prior to the snake appearing at the nest (this was the one diurnal snake predation), and at the other nest, the female abandoned the nest just after sunset, several hrs before the snake predation. A Mourning Dove (Zenaida macroura) nest 
located just below this nest was depredated the same night suggesting the female may have flushed from and possibly abandoned the nest due to the presence of a predator below her. Four of $17(23 \%)$ snake nest predations during the nestling stage resulted in predation of the female and occurred while the nestlings were young ( $\leq 5$ days old) and in need of brooding. Eleven $(65 \%)$ snake nest predations occurred late in the nestling stage when females were no longer brooding. Four of these nest predation events caused at least one nestling to prematurely fledge ('force-fledge') and two nests had already fledged young prior to the snake predation event. Females were present but escaped the remaining two (12\%) snake nest predations. Both nests contained 5or 6-day old nestlings. The female was brooding at one nest and left the nest as the snake appeared in view. This predation event occurred about 30 min after sunset while the female was still alert. She peered below the nest $3 \mathrm{~min}$ prior to the snake appearing on camera and flew off the nest as the snake approached. The female at the other nest was sleeping on the rim of the nest and was actually pushed off the nest by the snake as it investigated the nestlings. The snake lurched after the falling female, but when it returned to view at the nest seconds later, it did not appear to have caught the female. This female was not seen returning to the nest. Females were preyed upon during $29 \%(6 / 21)$ of the total snake nest predations, $67 \%(6 / 9)$ of the times they were present during the nest predation, and $75 \%$ (6/ 8) of the nocturnal nest predations for which the female was at the nest.

\section{DISCUSSION}

Snakes consumed females attending the nest during the majority of nest predation events for which females were present, a finding no other study has reported for a songbird. Predation by snakes on female Goldencheeked Warblers attending the nest likely represents an important source of mortality during the breeding season for this species. Rat snakes are well-known tree climbers (Tennant 1998) and would not be deterred from climbing trees with rough bark (Mullin and Cooper 2002) such as Ashe juniper. A study documenting nest predators of Black-capped Vireos (Vireo atricapillus) at Fort Hood also identified Texas rat snakes as the most frequent predator, responsible for 18 of 48 nest predation events (Stake and Cimprich 2003). However, no nest predation by a snake resulted in depredation of an adult. Black-capped Vireos nest in shrubs and the nesting substrate is likely not as stable or sturdy as that of Golden-cheeked Warblers. Adults spending the night at the nest in shrubs would more likely be alerted to an approaching predator.

Little is known about adult survival for Golden-cheeked Warblers, particularly females, and we cautiously speculate about possible implications on population dynamics. Pairing success is commonly used as an indicator of habitat quality with presence of unpaired males suggesting low habitat quality (Gibbs and Faaborg 1990, Bayne and Hobson 2001). Golden-cheeked Warbler pairing success is generally high (often $\geq 90 \%$ ) for territorial males at sites considered to be highquality habitat (Jetté et al. 1998; Becker 2006; Peak 2006; J. L. Reidy, unpubl. data), while lower quality habitat in Austin had low (20$33 \%$ ) pairing success (Becker 2005, 2006). Pairing success was also lower for secondyear males than older males at Fort Hood (Jetté et al. 1998). These observations of differential pairing success are indicative of a population with a lower number of females than males, and we suggest female-biased mortality during the breeding season may be a contributing factor. Better estimates of adult and juvenile survival for males and females, pairing success, and existence and extent of potential non-territorial, or "floater" males (Bayne and Hobson 2001) are necessary to examine if predation on adult females during the breeding season affects long-term stability of Golden-cheeked Warbler populations.

Predation of adult females at the nest may partially explain the skewed adult survival rates and sex-ratios exhibited by many songbirds. Wood Thrush (Hylocichla mustelina) females had lower survival rates than males during the breeding season (Powell et al. 2000, Coulter 2005). Survival was also lower for Black-throated Blue Warbler (Dendroica caerulescens) females than males during the breeding season (Sillett and Holmes 2002) and Ovenbird (Seiurus aurocapillus) females had lower annual survival estimates than males (Bayne and Hobson 2002). Many mi- 
grant songbird populations exhibit male-biased sex-ratios during the breeding season (Gibbs and Faaborg 1990, Villard et al. 1993, Van Horn et al. 1995). Migrant songbird populations can be more sensitive to changes in adult survival than juvenile or nest survival (Noon and Sauer 1992, Donovan and Thompson 2001). The loss of substantial numbers of breeding females to predators simultaneous to nest failure may be calamitous, especially for an endangered species. Extinction risk for endangered species is greater for populations with male-biased sex-ratios (Donald 2007) and for small, isolated populations experiencing recent habitat fragmentation (Dale 2001).

Songbirds nesting in climates hospitable to snakes, particularly those exhibiting nocturnal foraging patterns such as rat snakes, may be particularly vulnerable to predation while on the nest (Carter et al. 2007). Open-cup nesters may have more opportunity to escape than cavity nesters, but species which nest on sturdy substrates, such as Golden-cheeked Warblers, or on the ground, may not detect a predator in time to escape, especially during the night. We suspect more nesting studies using time-lapse video surveillance in geographic regions with nocturnal snakes will reveal additional predation on incubating and brooding adult songbirds. We believe adult mortality during the breeding season warrants further investigation for other species and ecosystems.

\section{ACKNOWLEDGMENTS}

We thank John Cornelius and the Department of the Army, Fort Hood and Tim Hayden and the Army Engineer Research and Development Center for funding and other support. Richard Aracil, Kyla Ercit, Mark Faherty, Nicole Flood, Allen Graber, Carter Mullen, Charles Pekins, Scott Stollery, Diane Tracy, Maria Elena Tolle, and Michael Wickens provided field assistance. We are grateful to biologists with The Nature Conservancy and the City of Austin for assistance and support. We thank the U.S. Forest Service Northern Research Station and the Missouri Cooperative Fish and Wildlife Research Unit (U.S. Geological Survey, Missouri Department of Conservation, University of Missouri, and U.S. Fish and Wildlife Service) for their support. Information included in this manuscript does not necessarily reflect the position or policy of the U.S. Government or The Nature Conservancy, and no official endorsement should be inferred.

\section{LITERATURE CITED}

Bayne, E. M. And K. A. Hobson. 2001. Effects of habitat fragmentation on pairing success of Ovenbirds: importance of male age and floater behavior. Auk 118:380-388.

Bayne, E. M. And K. A. Hobson. 2002. Annual survival of adult American Redstarts and Ovenbirds in the southern boreal forest. Wilson Bulletin 114: $358-367$.

BECKER, H. M. 2005. 2005 Golden-cheeked Warbler Dendroica chrysoparia and Black-capped Vireo Vireo atricapillus monitoring program. Pages 4 11 in Balcones Canyonlands Preserve Annual Report 2004-2005. City of Austin, Texas, USA.

BECKER, H. M. 2006. 2006 Golden-cheeked Warbler Dendroica chrysoparia and Black-capped Vireo Vireo atricapillus monitoring program. Pages 3 11 in Balcones Canyonlands Preserve Annual Report 2005-2006. City of Austin, Texas, USA.

BLEM, C. R. 1979. Predation of black rat snakes on a Bank Swallow colony. Wilson Bulletin 91:135137.

Carter, G. M., M. L. Legare, D. R. Breininger, AND D. M. ODDY. 2007. Nocturnal nest predation: a potential obstacle to recovery of a Florida ScrubJay population. Journal of Field Ornithology 78: 390-394.

CARTER, W. A. 1992. Black-and-white Warbler nest failure in Pontotoc County, Oklahoma. Bulletin of the Oklahoma Ornithological Society 25:22-23.

Coulter, S. C. 2005. Effects of forest management on Wood Thrushes in the Atchafalaya Basin, Louisiana. Thesis. University of Arkansas, Fayetteville, USA.

DALE, S. 2001. Female-biased dispersal, low female recruitment, unpaired males, and the extinction of small and isolated bird populations. Oikos 92: 344-356.

Donald, P. F. 2007. Adult sex ratios in wild bird populations. Ibis 149:671-692.

Donovan, T. M. AND F. R. Thompson III. 2001. Modeling the ecological trap hypothesis: a habitat and demographic analysis for migrant birds. Ecological Applications 11:871-882.

FENDLEY, T. T. 1980. Incubating Wood Duck and Hooded Merganser hens killed by black rat snakes. Wilson Bulletin 92:526-527.

Flaspohler, D. J., S. A. Temple, and R. N. RosenFIELD. 2001. Species-specific edge effects on nest success and breeding bird density in a forested landscape. Ecological Applications 11:32-46.

GibBS, J. P. AND J. FAABORG. 1990. Estimating the viability of Ovenbird and Kentucky Warbler populations in forest fragments. Conservation Biology 4:193-196.

Grant, T. A., T. L. Shaffer, E. M. Madden, And P. J. PIETZ. 2005. Time-specific variation in passerine nest survival: new insights into old questions. Auk 122:661-672.

Hensley, R. C. And K. G. Smith. 1986. Eastern Blue- 
bird responses to nocturnal black rat snake nest predation. Wilson Bulletin 98:602-603.

Jetté, L. A., T. J. HAyden, AND J. D. Cornelius. 1998. Demographics of the Golden-cheeked Warbler (Dendroica chrysoparia) on Fort Hood, Texas. U.S. Army Construction Engineering Research Laboratories Technical Report 98/52. Champaign, Illinois, USA.

KING, D. I. 1999. Mortality of an adult Veery incurred during defense of nestlings. Wilson Bulletin 111: 576-77.

LADD, C. AND L. GASS. 1999. Golden-cheeked Warbler (Dendroica chrysoparia). The birds of North America. Number 420.

LASKEY, A. R. 1946. Snake depredations at bird nests Wilson Bulletin 58:217-218.

MAHAN, H. D. 1956. Nocturnal predation on Song Sparrow eggs by milksnake. Wilson Bulletin 68: 245.

Mullin, S. J. AND R. J. CoOper. 2002. Barking up the wrong tree: climbing performance of rat snakes and its implications for depredation of avian nests. Canadian Journal of Zoology 80:591-595.

Noon, B. R. AND J. R. SAUER. 1992. Population models for passerine birds: structure, parameterization, and analysis. Pages 441-464 in Wildlife 2001: Populations (D. R. McCullough and R. H. Barrett, Editors). Elsevier Applied Science, New York, USA.

PEAK, R. G. 2006. Demography of the Golden-cheeked Warbler on Fort Hood, Texas, 2006. Pages 72-94 in Endangered species monitoring and management at Fort Hood, Texas: 2006 annual report. The Nature Conservancy, Fort Hood Project, Fort Hood, Texas, USA.

PEAK, R. G. 2007. Forest edges negatively affect Golden-cheeked Warbler nest survival. Condor 109: 628-637.

PetTingill JR., O. S. 1976. Observed acts of predation on birds in northern Lower Michigan. Living Bird $15: 33-41$

Pietz, P. J. AND D. A. Granfors. 2000. Identifying predators and fates of grassland passerine nests using miniature video cameras. Journal of Wildlife Management 64:71-87.

Plummer, M. V. 1977. Predation by black rat snakes in Bank Swallow colonies. Southwestern Naturalist 22:147-148.

Powell, L. A., J. D. Lang, M. J. Conroy, And D. G. KREMENTZ. 2000. Effects of forest management on density, survival, and population growth of Wood Thrushes. Journal of Wildlife Management 64:1123.

Pulich, W. M. 1976. The Golden-cheeked Warbler: a bioecological study. Texas Parks and Wildlife Department, Austin, USA.

QuinN, J. S. 1985. Caspian Terns respond to rattle- snake predation in a colony. Wilson Bulletin 97: 233-234.

REIDY, J. L. 2007. Golden-cheeked Warbler nest success and nest predators in urban and rural landscapes. Thesis. University of Missouri, Columbia, USA.

Reidy, J. L., M. M. Stake, AND F. R. Thompson III. 2008. Golden-cheeked Warbler nest mortality and predators in urban and rural landscapes. Condor 110:458-466.

SAS InSTITUTE. 2004. The SAS system for Windows. Version 9.1. SAS Institute Inc., Cary, North Carolina, USA.

SHAFFER, T. L. 2004. A unified approach to analyzing nest success. Auk 121:526-540.

ShafFer, T. L. AND F. R. ThOMPSON III. 2007. Making meaningful estimates of nest survival with modelbased methods. Studies in Avian Biology 34:8495.

SHERRY, T. W. AND R. T. Holmes. 1997. American Redstart (Setophaga ruticilla). The birds of North America. Number 277.

Sillett, T. S. AND R. T. Holmes. 2002. Variation in survivorship of a migratory songbird throughout its annual cycle. Journal of Animal Ecology 71: 296-308.

Stake, M. M. 2003. Golden-cheeked Warbler nest predation. Thesis. University of Missouri, Columbia, USA.

Stake, M. M. AND D. A. Cimprich. 2003. Using video to monitor predation at Black-capped Vireo nests. Condor 105:348-357.

Stake, M. M., J. FaAborg, and F. R. Thompson III. 2004. Video identification of predators at Goldencheeked Warblers nests. Journal of Field Ornithology 75:337-344.

Tennant, A. 1998. A field guide to Texas snakes. Gulf Publishing Company, Houston, Texas, USA.

Thompson III, F. R. 2007. Factors affecting nest predation on forest songbirds in North America. Ibis 149:98-109.

Thompson III, F. R., W. DiJak, and D. E. Burhans. 1999. Video identification of predators at songbird nests in old fields. Auk 116:259-264.

U.S. Department of InTERIOR (USDI). 1992. Goldencheeked Warbler (Dendroica chrysoparia) recovery plan. USDI, Fish and Wildlife Service, Albuquerque, New Mexico, USA.

VAn Horn, M. A., R. M. Gentry, AND J. FAaborg. 1995. Patterns of Ovenbird (Seiurus aurocapillus) pairing success in Missouri forest tracts. Auk 112: 98-106.

Villard, M.-A., P. R. Martin, and C. G. Drummond. 1993. Habitat fragmentation and pairing success in the Ovenbird (Seiurus aurocapillus). Auk 110: 759-768. 


\title{
Depredation of Black-throated Blue Warbler Nestlings by an Introduced Slug (Arionidae)
}

\author{
Traynor G. Biasiolli ${ }^{1}$
}

\begin{abstract}
Black-throated Blue Warblers (Dendroica caerulescens) are subject to nest predation by a variety of avian and mammalian species. I present evidence that slugs (Gastropoda: Mollusca) can also function as nest predators. On two occasions, slugs were observed feeding on 6-7 day-old nestling Blackthroated Blue Warblers at Hubbard Brook Experimental Forest, New Hampshire, USA. This is apparently the first report documenting that slugs can function as avian nest predators. Received 22 February 2008. Accepted 25 December 2008.
\end{abstract}

Black-throated Blue Warblers (Dendroica caerulescens) are shrub-nesting Nearctic-neotropical migrant passerines. These warblers are subject to nest predation by a wide variety of mammals and birds, including red squirrels (Tamiasciurus hudsonicus), eastern chipmunks (Tamias striatus), Blue Jays (Cyanocitta cristata), and Sharp-shinned Hawks (Accipiter striatus) (Holmes et al. 2005). Slugs are rarely but consistently noted in or on Black-throated Blue Warbler nests at a study site in New Hampshire, USA (R. T. Holmes, unpubl. data). However, no evidence exists to indicate that slugs can function as avian nest predators. I present evidence that, at least in rare instances, slugs will feed on nestling Black-throated Blue Warblers.

\section{OBSERVATIONS}

Observations were made during summer 2006 at the Hubbard Brook Experimental Forest $\left(43^{\circ} 56^{\prime} \mathrm{N}, 71^{\circ} 45^{\prime} \mathrm{W}\right)$, a 3,160 -ha reserve within the White Mountain National Forest. Black-throated Blue Warblers have been intensively studied at Hubbard Brook and more than 2,900 nests have been monitored since 1986 (Holmes et al. 2005).

On 24 June 2006, during a routine nest check, a field technician found a nest that had

1223 Cooksboro Road, Troy, NY 12182, USA; e-mail: tbiasiolli@yahoo.com disintegrated, and the three nestlings were on the ground underneath the nest. The nest had apparently been damaged by heavy rains the previous day, and the nestlings had fallen through the nest bottom. The nestlings were 7 days of age and too young for independent movement (Black-throated Blue Warbler nestlings generally fledge 9 days after hatching; Holmes et al. 2005). All nestlings were still alive, although a slug was attached to each bird. One slug was attached to the upper wing of a nestling, while the other two slugs were each attached to the underside of a nestling wing. The nestlings were likely weakened due to their poor ability to thermoregulate. However, they were sufficiently strong to beg actively for food, and showed no evidence of injury other than lesions where the slugs were attached. Both parents were nearby, attempting to feed the nestlings. The field assistant at the site decided to remove the slugs, and replaced the nestlings in the remnants of the nest. None of the nestlings were observed during the subsequent nest check 2 days later, and the adults had begun building a replacement nest. The principal cause of apparent nestling mortality is unclear.

A second observation occurred on 4 August 2006 at a second study area within Hubbard Brook, $\sim 5 \mathrm{~km}$ from the site of the first observation. As I approached a nest during a routine nest check, I observed a slug inside the nest actively feeding on a nestling. All four nestlings in the nest had suffered severe disfiguration, and three had died by the time I arrived. The remaining live nestling was weakly attempting to beg for food, despite its injuries. The slug was feeding on a nestling which had already died, and I did not observe a slug feeding on the remaining live nestling. The pattern of disfigurement found on all nestlings was inconsistent with damage previously observed in depredated nests at Hubbard Brook (R. T. Holmes, N. L. Rodenhouse, and 
T. S. Sillett; pers. comm.), suggesting the slug was the sole source of damage to the nestlings. Specifically, all four nestlings had suffered the complete loss of at least one eye, and two nestlings, including the live nestling, had suffered damage to their bills. Eyes were cleanly removed rather than partially pecked or chewed, and no scratches or cuts were evident near the eyes. Damage to the nestlings' bills was extensive with approximately twothirds of the upper mandible consumed on the live nestling. I observed no scratches or cuts near the bills, which would be consistent with evidence of an avian or mammalian predator. The nest was still being attended by the female, although the male had deserted. Male Black-throated Blue Warblers frequently abandon nests after late July, but females can typically raise late-season young without male assistance when food levels are sufficient, as they were in late July 2006 (Holmes et al. 2005; R. T. Holmes, unpubl. data). Thus, it is unlikely the nestlings had been weakened or died due to starvation prior to being consumed by the slug.

\section{DISCUSSION}

The slugs observed in both instances were members of the genus Arion (Arionidae), presumably the same species. This genus is native to Europe, but many Arion species have successfully established populations in North America (Chichester and Getz 1973). The slugs observed were most likely A. subfuscus, which has been previously documented at Hubbard Brook (Strayer et al. 1986; T. A. Pearce, pers. comm.).

A thorough search of the ornithological and malacological literature revealed no prior evidence of slugs feeding on birds, nor on other live vertebrate prey. Most terrestrial slugs, including Arionidae, feed primarily on plant and fungal matter (South 1992). However, Arion consume a wide variety of food items, including food of animal origin such as mammal and bird carcasses, dead invertebrates, and conspecifics (Boycott 1934, South 1992).

It is perhaps surprising that slugs have not been previously documented as nest predators given their wide dietary breadth and ability to consume animal matter. However, the predation events described may represent unusual circumstances. The nestlings in the first incident had fallen from their nest onto the ground. Slugs were much more likely to encounter the nestlings outside of the nest, and the adults may have been less able or willing to dislodge slugs from their young on the ground. In the second instance, the male had abandoned the nest and the task of nest defense was left to the female. Previous observations of this nest indicated the female was extraordinarily wary, and may have been too skittish or inattentive to attack or drive off the slug. It is likely that when slugs encounter nests during the nestling stage, adults will successfully repel slugs, and slugs may only function as nest predators under atypical circumstances.

\section{ACKNOWLEDGMENTS}

My research was supported by a grant from the U.S. National Science Foundation to R. T. Holmes, N. L. Rodenhouse, and T. S. Sillett and a U.S. Department of Agriculture McIntire-Stinnis grant to the University of Vermont. I thank the Hubbard Brook Experimental Forest of the U.S. Department of Agriculture's Northeast Research Station for support and cooperation. This manuscript benefited from comments of T. S. Sillett, A. M. Strong, M. H. Cline, W. S. Schwenk, N. G. Perlut, S. J. K. Frey, and N. J. Zalik, as well as two anonymous referees. K. P. Hotopp, T. A. Pearce, and G. L. Bernon provided valuable assistance with slug identification.

\section{LITERATURE CITED}

Boyсотт, A. E. 1934. The habitats of land Mollusca in Britain. Journal of Ecology 22:1-38.

Chichester, L. F. And L. L. Getz. 1973. The terrestrial slugs of northeastern North America. Sterkiana 51:11-42.

Holmes, R. T., N. L. Rodenhouse, and T. S. Sillett. 2005. Black-throated Blue Warbler (Dendroica caerulescens). The birds of North America. Number 87 .

South, A. 1992. Terrestrial slugs: biology, ecology, and control. Chapman and Hall, London, United Kingdom.

Strayer, D., D. H. Pletscher, S. P. Hamburg, and S. C. NoDvin. 1986. The effects of forest disturbance on land gastropod communities in northern New England. Canadian Journal of Zoology 64:20942098. 
The Wilson Journal of Ornithology 121(2):424-426, 2009

\title{
Nest Sharing between an American Robin and a Northern Cardinal
}

\author{
Paul W. Govoni, ${ }^{1,2}$ Keith S. Summerville, ${ }^{1,4}$ and Muir D. Eaton ${ }^{3}$
}

\begin{abstract}
Mixed-clutch nest sharing was observed between an American Robin (Turdus migratorius) and a Northern Cardinal (Cardinalis cardinalis) in Saylor Township, Polk County, Iowa in May 2007. The nest contained three American Robin eggs and two Northern Cardinal eggs, but only American Robin young were fledged successfully. This was not a case of brood parasitism, as both females were observed alternating incubation of the nest. Competition for desirable nest sites might be a possible cause for this type of interspecific behavior. Received 17 July 2008. Accepted 15 October 2008.
\end{abstract}

Both intra- and interspecific interactions among birds can have significant influences on nesting success. For example, brood sharing, brood parasitism, nest usurpation, and interspecific feeding have been documented among passerines (Payne 1977). Nest usurpation is often restricted to species with enclosed or cavity nests (Lindell 1996), but other interactions have been observed across a variety of cup-nesting species (e.g., Payne 1977, Shy 1982, McNair 1984). Brood parasitism of Northern Cardinal (Cardinalis cardinalis) is known to occur, mainly from Brown-headed Cowbirds (Molothrus ater) (Halkin and Linville 1999). Intraspecific brood sharing has also been observed between two female Northern Cardinals, and was attributed to fertilization of both by the same male (Rice 1969). Cardinals have also exhibited intraspecific cooperative breeding behavior among unrelated individuals (Halkin and Linville 1999), as well as an instance of feeding of American Robin (Turdus migratorius) young (Shy 1982). American Robins, however, are less tolerant of nest violations, gen-

\footnotetext{
${ }^{1}$ Department of Environmental Science, Drake University, Des Moines, IA 50311, USA.

${ }^{2}$ Current address: 5800 NE 6th Street, Des Moines, IA 50313, USA.

${ }^{3}$ Department of Biology, Drake University, Des Moines, IA 50311, USA.

${ }^{4}$ Corresponding author; e-mail:

keith.summerville@drake.edu
}

erally rejecting Brown-headed Cowbird eggs (but see Lowther 1981), and have not been observed to exhibit intraspecific cooperative brood care (Sallabanks and James 1999).

Examples of interspecific nest sharing, where eggs from both species are present in the nest and/or cared for by both species, are less commonly documented, but not absent from the literature (e.g., Cohen 1899, Atkins 1916, Bleitz 1956, Crowell et al. 1982). One example of this phenomenon documented a clutch of 17 larger and nine smaller eggs being jointly incubated by a female Greater Scaup (Aythya marila) and a female Lesser Scaup (A. affinis) on Great Slave Lake (Fournier and Hines 1996). The eggs were positioned in the nest so both females could sit side by side, in contact with each other, and incubate all of the eggs simultaneously (Fournier and Hines 1996). Mixed clutches have also resulted in mixed broods; during a 10year field investigation of cavity nesting species, Robinson et al. (2005) observed fledglings of both Red-breasted Nuthatches (Sitta canadensis) and Mountain Chickadees (Poecile gambeli) after adults of both species had exhibited parental behavior at a single nest. We report a case of interspecific nest sharing and brood care by a pair of Northern Cardinals and a pair of American Robins.

\section{OBSERVATIONS}

On 3 May 2007, PWG observed an American Robin in a nest constructed $\sim 1 \mathrm{~m}$ above ground level in a 2-m tall Sunkist Arborvitae (Thula occidentalis "Sunkist"). The evergreen was in a suburban development, $2 \mathrm{~m}$ from a house and adjacent to a raised wooden deck. The nest was partially sheltered by these structures. The surrounding neighborhood lacked mature trees or much shrub cover. On 4 May 2007, a female Northern Cardinal was observed using the same nest. These two birds changed their respective occupation of the nest frequently and, while each was away 


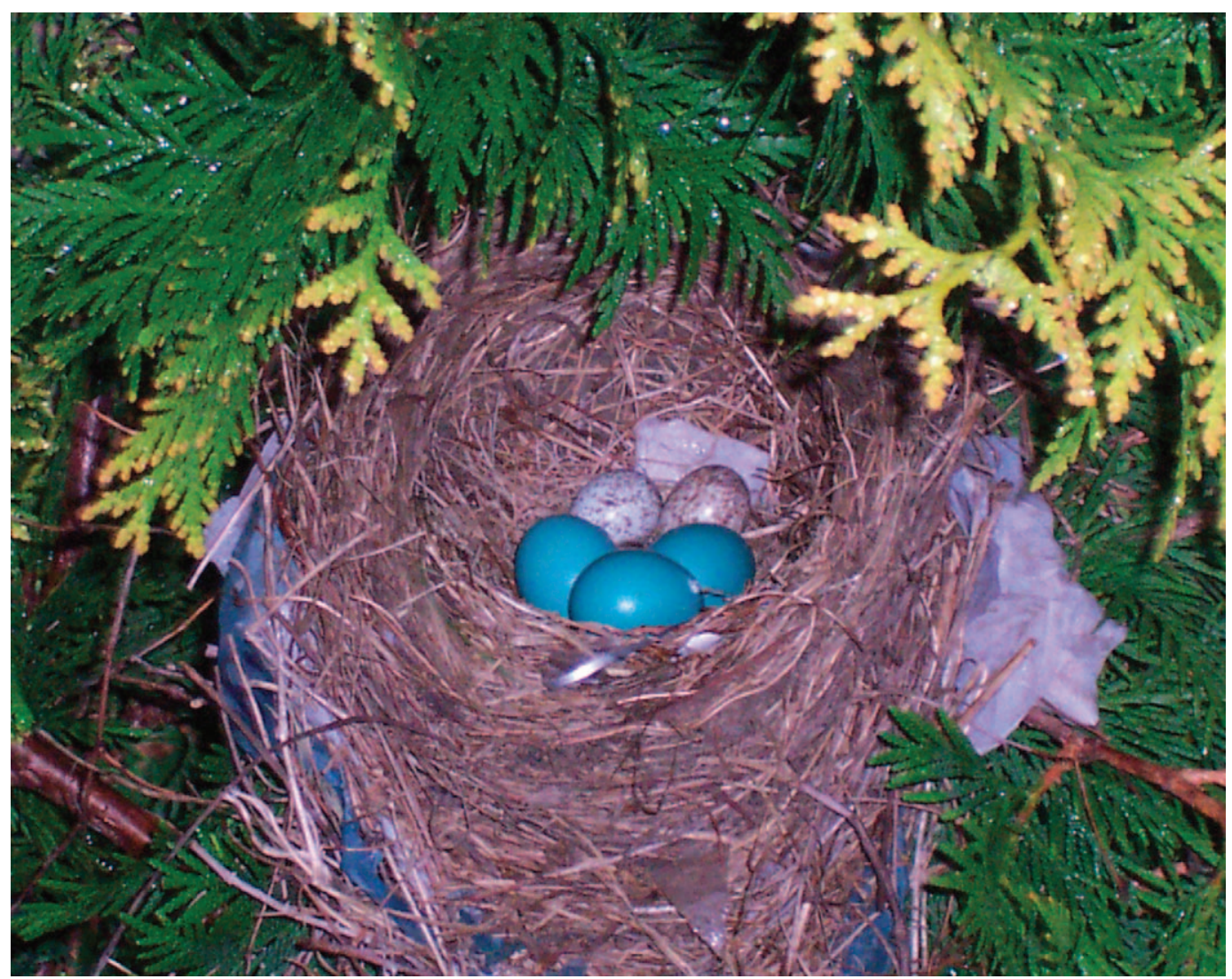

FIG. 1. American Robin and Northern Cardinal eggs incubated in the same nest.

from the nest, were observed in close proximity to a conspecific male. These males were presumed to be the mates of each female, which was confirmed for the cardinal by subsequent observations.

Examination of the nest on 5 May 2007 revealed three robin eggs and two cardinal eggs (Fig. 1). The nest was monitored ad hoc over the next week to document incubation. Regular shifting of females on the nest continued during this period, however, the distance between the females and the nest continually decreased. Quite often, the female cardinal would return to the nest to find the robin on the eggs and perch several centimeters away on a limb. As time progressed, it was common to see both the female cardinal and the female robin in the nest at the same time. This practice appeared to cease when the female cardinal began to display aggressive behaviors toward the robin. If the female cardinal re- turned to the nest and found the robin there, the cardinal would stand on the back of the robin and scratch and kick until the robin fled the nest. During this time, it was also common to observe the male cardinal bringing food to the female while she sat on the nest.

A fledgling appeared in the nest on 14 May 2007, and both females continued to share nest time, with the male cardinal continuing to feed the female while she roosted on the nest. A second fledgling was present in the nest on 16 May 2007. From this point forward, the cardinals were no longer seen at the nest. Subsequent inspection of the nest revealed only the two fledglings and remains of a single cardinal egg on the ground directly beneath the nest. The two fledglings continued to develop under parental care of the robin, only, and were recognizable as juvenile American Robins on 22 May 2007. The juveniles eventually forayed onto the deck from the nest 
and in a matter of days were no longer seen in the area, as was true of the parents.

\section{DISCUSSION}

The nesting strategy that uses the active takeover of a nest site of one species by a different species for egg laying and incubation is known as nest usurpation or nest piracy. This particular behavior is not in agreement with the popular belief that coexisting species have divergent nest placement (Lindell 1996). However, studies have also concluded that convergence upon a nest site by more than one species is evidence of interspecific competition for nesting sites (Lindell 1996). The nesting behavior we observed demonstrates a single nest site can be suitable for more than one species. Whether the cardinal pair observed in this instance was two juvenile birds with little nesting experience or was competitively inferior to the robin pair are unresolved questions. The aggressive nature of this particular observation suggests the value of nesting sites in suburban habitats is worth protracted physical confrontation. The Northern Cardinal may use an aggressive re-nesting strategy in response to high levels of nest predation (Filliater et al. 1994), and the selective pressures that affect the evolution of nest site selection require further research for both species.

\section{ACKNOWLEDGMENTS}

We thank C. E. Braun, M. M. Robbins, and two anonymous reviewers for constructive comments on this note that greatly improved the manuscript. S. K. Govoni contributed observations to our own and thus expanded our understanding of the nesting behavior of these two species.

\section{LITERATURE CITED}

AtKINs, E. 1916. A nestful. Condor 38:201-202.

BleitZ, D. 1956. Eggs of the California Quail in the nest of a Spotted Towhee. Condor 58:77-78.

Cohen, D. A. 1899. Nesting and other habits of the Oregon Towhee. Condor 1:61-63.

Crowell, D. K., C. C. Carpenter, and D. G. HufFMAN. 1982. Nest-sharing by a Lark Sparrow. Auk 99:591-592.

Filliater, T. S., R. Breitwisch, and P. M. Nealen. 1994. Predation on Northern Cardinal nests: does choice of nest site matter? Condor 96:761-768.

Fournier, M. A. AND J. E. Hines. 1996. Nest sharing by a Lesser Scaup and a Greater Scaup. Wilson Bulletin 108:380-381.

HaLkin, S. L. AND S. U. LinviLLE. 1999. Northern Cardinal (Cardinalis cardinalis). The birds of North America. Number 440.

LindELL, C. 1996. Patterns of nest usurpation: when should species converge on nest niches? Condor 98:464-473.

LOwTHER, P. E. 1981. American Robin rears Brownheaded Cowbird. Journal of Field Ornithology 52: 145-147.

MCNAIR, D. B. 1984. Reuse of other species' nests by Lark Sparrows. Southwestern Naturalist 29:506509.

PAYNe, R. B. 1977. The ecology of brood parasitism in birds. Annual Reviews of Ecological Systems $8: 1-28$.

Rice, O. O. 1969. Record of female Cardinals sharing nest. Wilson Bulletin 81:216.

Robinson, P. A., A. R. Norris, AND K. Martin. 2005. Interspecific nest sharing by Red-breasted Nuthatch and Mountain Chickadee. Wilson Bulletin 117:400-402.

SAllabanks, R. AND F. C. JAMES. 1999. American Robin (Turdus migratorius). The birds of North America. Number 462.

SHY, M. M. 1982. Interspecific feeding among some birds: a review. Journal of Field Ornithology 53: 370-393. 


\title{
Misdirected Parental Care by a Male Eastern Towhee at a Wood Thrush Nest
}

\author{
Kelly M. Schaeffer, ${ }^{1,3}$ William P. Brown, ${ }^{2}$ and W. Gregory Shriver ${ }^{1}$
}

\begin{abstract}
Misdirected parental care, or care directed toward unrelated young, has been recorded for many bird species. The Wood Thrush (Hylocichla mustelina) is not known to practice this behavior or allow other species to attend to its young. We observed a Wood Thrush nest with three Wood Thrush nestlings and one Brown-headed Cowbird (Molothrus ater) nestling being attended by a male Eastern Towhee (Pipilo erythrophthalmus). The towhee fed the young of both species in the nest for at least 5 days and was subsequently observed feeding a Wood Thrush fledgling. The towhee also participated in nest maintenance and defense. The proximate cause of towhee attendance at the Wood Thrush nest remains unknown, but begging calls from the nestlings may have stimulated the behavior. Received 28 June 2008. Accepted 3 November 2008.
\end{abstract}

Misdirected parental care is intra- or interspecific care directed toward the young of an unrelated bird (Shy 1982, Price et al. 1983). Misdirected parental care differs from interspecific feeding, which also may include an adult of one species feeding an adult of another species (Boix-Hinzen 1997). Misdirected parental care has been described several times for the Eastern Towhee (Pipilo erythrophthalmus), but Wood Thrushes (Hylocichla mustelina) are not known to exhibit this behavior or cooperate as recipients of the behavior in the wild. Skutch (1961) reported an adult male Wood Thrush helped feed nestlings of several different species in an aviary. Shy (1982) reported four occurrences of the Eastern Towhee feeding young of other species, including Field Sparrow (Spizella pusilla), Northern Mockingbird (Mimus polyglottos), and House Finch (Carpodacus mexicanus).

${ }^{1}$ Department of Entomology and Wildlife Ecology, 250 Townsend Hall, University of Delaware, Newark, DE 19716, USA.

2254 East Walnut Street, Kutztown, PA 19530, USA.

${ }^{3}$ Corresponding author; e-mail:

kmschaeffer@gmail.com
We report the first case of Wood Thrush nestlings in a nest parasitized by the Brown-headed Cowbird (Molothrus ater) being fed by a male Eastern Towhee.

Wood Thrush nests were located and monitored during the 2006 field season as part of a long-term study of Wood Thrush breeding ecology in the 15-ha University of Delaware Woods (UDW) in Newark, Delaware (Brown and Roth 2002, 2009). Individually colorbanded adults were associated with each nest and assumed to be the social parents of young Wood Thrushes in the nest. An 80-mm spotting scope was used to conduct observations from a blind approximately $15 \mathrm{~m}$ from the nest for at least $1 \mathrm{hr} /$ day for each of eight nests in a separate observational study (Schaeffer 2007). It was during these nest observations that KMS discovered a male Eastern Towhee feeding Wood Thrush nestlings and a Brownheaded Cowbird nestling in a Wood Thrush nest (Fig. 1).

\section{OBSERVATIONS}

The Wood Thrush nest of interest was discovered on 25 May 2006, $\sim 4.5 \mathrm{~m}$ aboveground in a shadbush (Amelanchier spp.), and contained three Wood Thrush eggs and two Brown-headed Cowbird eggs. Three thrushes and one cowbird hatched and survived to fledge.

We observed the male Eastern Towhee carrying food near the Wood Thrush nest during the first nest observation period for this nest on 14 June 2006, when the young were 8 days of age. The towhee did not approach the nest while the female was brooding, but remained on a branch $10-15 \mathrm{~cm}$ distant. The young thrushes were gaping while being brooded and the cowbird was begging loudly; these behaviors appeared to be directed at the towhee because all young were facing in his direction. Once the female Wood Thrush left the nest, the towhee approached the rim and fed one 


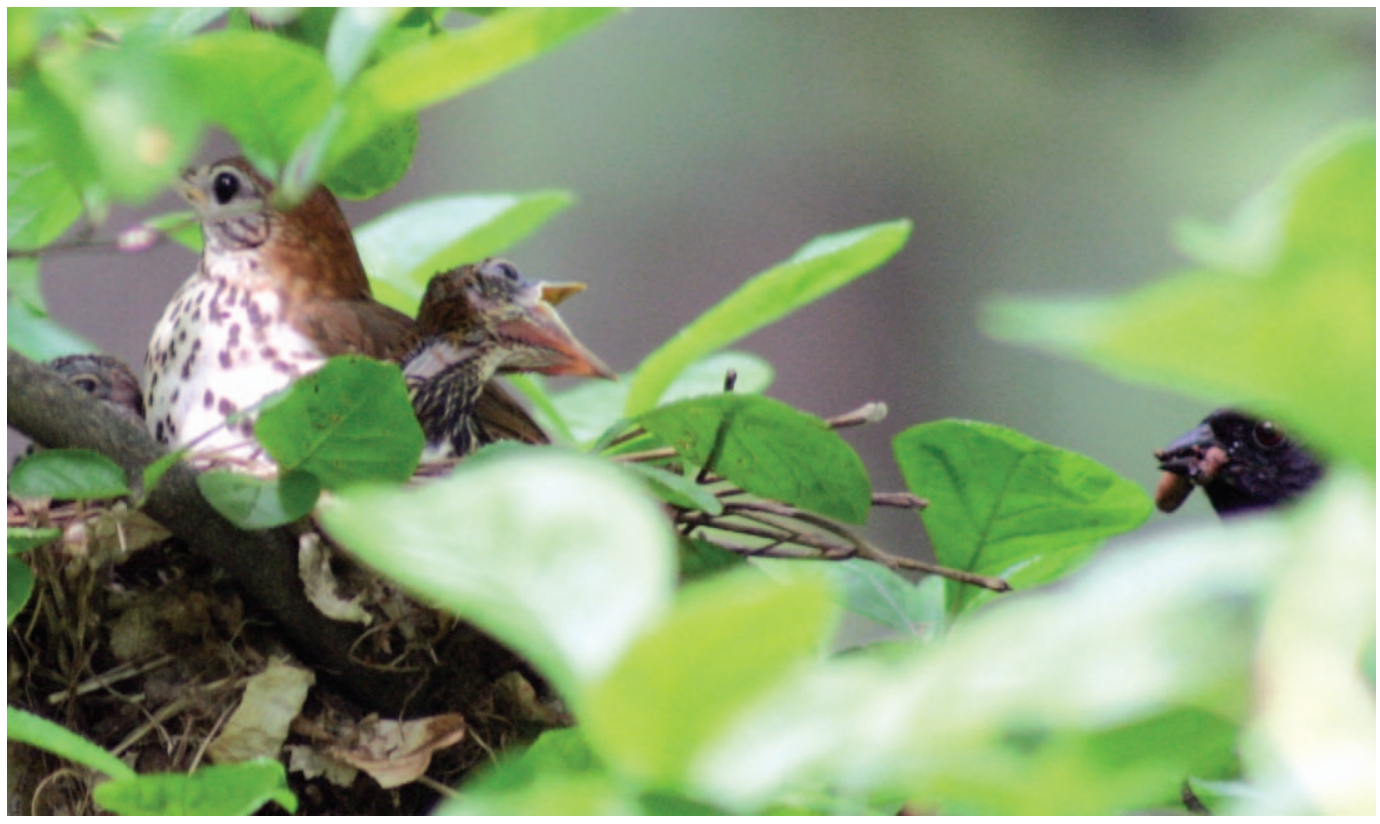

FIG. 1. Female Wood Thrush brooding her begging young as a male Eastern Towhee approaches the nest with food. Photograph by M. E. Zuefle and W. P. Brown, 2006.

young before quickly departing. The Wood Thrush parents did not react to the presence of the towhee. It is likely the towhee had been feeding the nestlings before 14 June based on the insistent begging behavior of the young at the approach of the towhee, the indifferent behavior of the Wood Thrush nest owners, and the rather direct route the towhee took to the nest.

The towhee participated in feeding and several other aspects of nest activity during the six subsequent 1 -hr observation periods from 15 June to 20 June. We removed the Wood Thrush nestlings for banding on 15 June, and the towhee called agitatedly while in close proximity to the Wood Thrush parents, which also were scolding. The towhee was observed removing fecal sacs from the nest on 16 June. The towhee continued to take part in nest defense on 17 June, responding to the presence of a Great Horned Owl (Bubo virginianus) $\sim 90 \mathrm{~m}$ from the nest. The towhee stood on the rim of the nest calling, while two Wood Thrushes, presumably the nest owners, scolded near the owl.

The Wood Thrush parents seldom reacted to the presence of the towhee over the course of our observations. The towhee approached the nest several times, remaining $\sim 5 \mathrm{~cm}$ from the rim, while the female was brooding on 16 June. She did not react to his presence, but the towhee did not try to feed the young. However, when the towhee approached the nest on 17 June while the female was brooding, he attempted to feed one of the nestlings. In response, the female Wood Thrush leaned over the rim and pecked at him. The towhee quickly flew from the nest tree, but remained in the area and returned with food as soon as the female had left the nest. The towhee made eight successful feeding trips while the Wood Thrush parents made seven trips collectively during the 1-hr observation period on 17 June. Both the towhee and female Wood Thrush fed the young on 19 June. The male Wood Thrush did not complete any feeding trips during this 1-hr observation period, but remained in the area singing almost continuously. The Eastern Towhee averaged 3.6 feeding trips/hr compared to the parents' combined 5.2 (2.6/adult) trips/hr for all observations.

The young fledged on the morning of 20 June, and the towhee was observed feeding a Wood Thrush fledgling in the nest tree, $\sim 3 \mathrm{~m}$ from the nest and $5 \mathrm{~m}$ above ground. The towhee was observed in the same area as the 
fledglings until 30 June, after which the fledglings were not observed in the area of the nest. The towhee was not observed feeding fledglings except for 20 June, but heavy cover precluded our efforts to successfully observe the fledglings being fed.

\section{DISCUSSION}

We observed misdirected parental care behavior by the male Eastern Towhee over a 7day period, including the first day the young fledged. Digital photographs of the towhee with food in his bill were taken near the nest on 18 June 2006 (Fig. 1). To our knowledge, this is the first report of Wood Thrushes being the recipient of misdirected parental care in the wild.

Wood Thrushes fledged at 12.3 days of age, on average, during the 2006 field season. The young attended by the towhee fledged at 13 days of age, suggesting the misdirected parental care did not affect nest success.

The circumstances that led the male Eastern Towhee to attend the Wood Thrush nest were unclear, as the breeding status of the towhee was not known. Shy (1982) described eight different categories that might stimulate misdirected parental care. These include the possibility that: (1) the bird practicing misdirected parental care was raising a mixed clutch, (2) the original nest of the bird was destroyed, (3) the nest of another species was close to that of the bird performing the behavior, (4) the calls of nestlings stimulated the misdirected parental care, (5) orphaned birds were adopted temporarily or permanently, (6) a male fed another species while his mate incubated, (7) finding a mateless bird, or being mateless itself, a bird joined a pair with young, or (8) reasons different from those given above.

The Brown-headed Cowbird regularly parasitizes both Wood Thrush and Eastern Towhee nests and the familiar sounds of a begging cowbird, or of nestlings in general, may have been the stimulus that triggered the towhee's feeding efforts. Brown-headed Cowbird parasitism was particularly heavy at UDW during 2006 (12 of 15 nests; Brown and Roth [2004] report annual rates of parasitism at UDW); the same may have been true for local towhee nests. Yoerg and O'Halloran (1991) and Dróżdż et al. (2004) reiterated the potential importance of begging sounds, as well as proximity to nests of other species, as a stimulus for misdirected parental care.

Shy (1982) reported that only 11 of 95 cases $(12 \%)$ of misdirected parental care involved the feeding of both nestlings and fledglings. Part of this rarity may be due to the difficulty of observing fledglings when they are being fed. The presumed rarity of misdirected parental care also may be due to the lack of systematic nest observations beyond recording the contents of the nest.

\section{ACKNOWLEDGMENTS}

We thank Vanessa Shiavi for help in the field and M. E. Zuefle for photography. KMS was supported by the University of Delaware Undergraduate Research Program and Science Scholars Program.

\section{LITERATURE CITED}

BoIX-HinzEN, C. 1997. Note on misdirected feeding behaviour. Lanioturdus 30:26-28.

Brown, W. P. AND R. R. Roth. 2002. Temporal patterns of fitness and survival in the Wood Thrush. Ecology 83:958-969.

BRown, W. P. AND R. R. Roth. 2004. Juvenile survival and recruitment of Wood Thrushes Hylocichla mustelina in a forest fragment. Journal of Avian Biology 35:316-326.

Brown, W. P. AND R. R. Roth. 2009. Age-specific reproduction and survival of individually marked Wood Thrushes, Hylocichla mustelina. Ecology 90: In press.

DróżDŻ, R., M. HromadA, AND P. TyranOwsKi. 2004. Interspecific feeding of Great Grey Shrike (Lanius excubitor) fledgling by adult Yellowhammers (Emberiza citronella). Biological Letters 41:185187.

Price, T., S. Millington, And P. Grant. 1983. Helping at the nest in Darwin's Finches as misdirected parental care. Auk 100:192-194.

SCHAEFFER, K. 2007. The effects of Brown-headed Cowbird parasitism on the parental feeding rates of Wood Thrush. Undergraduate Research Scholars Poster Session. University of Delaware, Newark, USA.

SHY, M. M. 1982. Interspecific feeding among some birds: a review. Journal of Field Ornithology 53: 370-393.

Skutch, A. F. 1961. Helpers among birds. Condor 63: 198-226.

Yoerg, S. I. AND J. O'Halloran. 1991. Dipper nestlings fed by a Gray Wagtail. Auk 108:427-429. 


\title{
Brood Rearing Ecology of King Eiders on the North Slope of Alaska
}

\author{
Laura M. Phillips ${ }^{1,4,5}$ and Abby N. Powell ${ }^{2,3}$
}

\begin{abstract}
We examined King Eider (Somateria spectabilis) brood survival in the Kuparak oil field in northern Alaska in 2002 and 2003 by monitoring hens with broods using radiotelemetry. We observed complete brood loss in eight of 10 broods. Broods survived less than 2 weeks on average, and most mortality occurred within 10 days of hatch. Distance hens traveled overland did not affect brood survival. Apparent King Eider brood survival in our study area was lower than reported for eider species in other areas. We recommend future studies examine if higher densities of predators in oil fields reduces King Eider duckling survival. Received 26 September 2008. Accepted 18 January 2009.
\end{abstract}

Declines in the North American population of King Eiders (Somateria spectabilis) have increased interest in the status and ecology of this species (Dickson et al. 1997, Gratto-Trevor et al. 1998, Suydam et al. 2000). King Eiders are circumpolar breeders that nest primarily along the margins of freshwater ponds and lakes on the arctic tundra (Suydam 2000). King Eider females leave the nest after hatch with their brood and move over land among tundra ponds (Bergman et al. 1977). Some waterfowl studies hypothesize that distance traveled over land may reduce duckling survival by increasing risk of mortality due to predation or exposure (Rotella and Ratti 1992, Seymore and Jackson 1996), while other studies suggest a positive correlation (Yerkes 2000, Mehl and Alisauskas 2007) or no effect (Wayland and McNicol 1994, Dzus and Clark 1997).

${ }^{1}$ Department of Biology and Wildlife, 211 Irving 1 Building, University of Alaska, Fairbanks, AK 99775 , USA.

${ }^{2}$ U.S. Geological Survey, Alaska Cooperative Fish and Wildlife Research Unit, P. O. Box 757020, University of Alaska, Fairbanks, AK 99775, USA.

${ }^{3}$ Institute of Arctic Biology, P. O. Box 757000, University of Alaska, Fairbanks, AK 99775, USA.

${ }^{4}$ Current address: Center for Resources, Science, and Learning, Denali National Park and Preserve, P. O. Box 9, Denali National Park, AK 99755, USA.

${ }^{5}$ Corresponding author; e-mail: laura_phillips@nps.gov
Estimates of duckling survival for waterfowl species suggest that survival rates are lower from hatching to fledging than during later life stages, and variation in survival is linked to recruitment (Mendenhall and Milne 1985, Johnson et al. 1992). Duckling mortality has been attributed to predation, adverse weather, starvation, and disease (Johnson et al. 1992). Identifying mortality at different life history stages is important for developing conservation plans for King Eiders. We examined survival of King Eider ducklings on the North Slope of Alaska and examined survival in relation to distance traveled over land.

\section{METHODS}

Study Area.-We trapped female King Eiders on nests in 2002 and 2003 at the Kuparuk oil field $\left(70^{\circ} 20^{\prime} \mathrm{N}, 149^{\circ} 45^{\prime} \mathrm{W}\right)$ between the Colville and Kuparuk rivers on the North Slope of Alaska. The site was characterized by numerous thaw lakes, ponds, and basins (Anderson et al. 1999).

Capture and Telemetry.-We searched accessible areas in the Kuparuk oil field for nesting King Eiders during each summer, 2002 and 2003. We candled and floated eggs from nests to assess incubation stage and estimate hatch date (Weller 1956). We monitored nests at least once per week.

We captured hens on nests about 1 week prior to hatch using hand-carried mist nets (Bacon and Evrard 1990) or bow-net traps (Sayler 1962). We originally planned to trap 20 randomly selected hens each year but, due to low nest success we attempted to trap any female still on a nest 1 week prior to predicted hatch date. We captured 12 females in 2002, clipped feathers on their upper back between their wings, and attached 8-g VHF transmitters (Telonics Inc., Mesa, AZ, USA) to the area using epoxy. We attached 10-g VHF anchor transmitters using a suture technique (Pietz et al. 1995) to 12 hens in 2003 to reduce transmitter loss. We checked nests daily after 
TABLE 1. King Eider radio-tracking at Kuparuk, Alaska, 2002-2003.

\begin{tabular}{|c|c|c|c|}
\hline & 2002 & 2003 & Total \\
\hline Females radio-marked & 12 & 12 & 24 \\
\hline Radio-marked females that failed to hatch eggs & 5 & 3 & 8 \\
\hline Radio-marked females that lost radio tag & 3 & 0 & 3 \\
\hline Females radio-tracked & 4 & 6 & 10 \\
\hline Radio-marked females that lost broods prior to first relocation & 0 & 3 & 3 \\
\hline
\end{tabular}

capture to document departure of broods. We did not flush hens from nests during these checks. We checked nests for number of hatched eggs when females departed the nest area following hatch. We assumed initial brood size was equal to the number of hatched shell membranes (Girard 1939). All methods and handling of birds were approved by the University of Alaska Institutional Animal Care and Use Committee (IACUC \# 02-10).

We located hens after hatch every 2-5 days until ducklings were 30 days of age or until we observed a female without a brood on two consecutive tracking sessions. We tracked marked hens by vehicle, foot, and aircraft. Aerial telemetry flights were used weekly when weather permitted to locate hens not found from the ground. Transmitters had a range of at least $1 \mathrm{~km}$ from the ground and up to 10 $\mathrm{km}$ from the air. We recorded location information using Global Positioning System (GPS) units and aerial photos. We used aerial photos to record locations when we were not able to get exact GPS locations or did not want to disturb hens with broods. We later returned to these locations to obtain locations using GPS or inferred locations using ArcView. We also recorded brood size, number of hens and ducklings if broods had formed crèches, and predators observed.

Analysis.-We plotted movements of females using ArcView 3.2 Geographic Information System (GIS) (ESRI 1998). We calculated straight line distances between re-observations and mean bearing of movement paths using Animal Movement extension (Hooge and Eichenlaub 1997) in ArcView. We considered survival of a brood as at least one duckling surviving to 30 days of age when King Eider ducklings closely resemble adults in size and mortality from predation is negligible (Mehl and Alisauskas 2007). We considered a marked hen observed in a crèche to still have a brood if ducklings of the appropriate age tended to follow her rather than alternate hens when disturbed. We calculated daily survival estimates for broods using the Mayfield method and assigned exposure days for complete brood loss equal to $50 \%$ of the last observation interval (Mayfield 1961, 1975, Johnson 1979). Survival to 30 days was calculated by raising the daily survival rate to the power of 30 .

We used linear regression to test whether the number of days a brood survived was affected by distances traveled over land and if distances traveled per day varied with duckling age. Data from both years were pooled in all analyses due to small sample sizes. We performed all statistical analyses using SAS software (SAS Institute 1990); means \pm SE are presented. Results were considered significant at $\alpha=0.05$.

\section{RESULTS}

Four of 12 hens captured in 2002 were successfully radio-tracked with broods, five failed to hatch eggs, and three prematurely lost their radio transmitters prior to first relocation after hatch (Table 1). Six of 12 hens captured in 2003 were successfully radio-tracked, three failed to hatch eggs, and three lost broods prior to first relocation after hatch (Table 1). We relocated marked hens with broods $5.6 \pm 1.4$ times $(n=10$, range $=1-14)$.

Average brood size at hatch was $4.2 \pm 0.4$ ducklings $(n=10$, range $=2-6)$. We observed complete brood loss in eight of 10 broods $(80 \%)$. Broods survived an average of $13.4 \pm 3.1$ days $(n=10$, range $=2-31)$. Most brood loss ( 5 of $8,62.5 \%$ ) occurred within the first 10 days after hatch (Table 2). The daily survival estimates for broods was $0.855 \pm$ 0.026 , and estimated survival over 30 days was $10.3 \%$ (95\% CI: 2.0-49.3). We observed the depredation of a King Eider chick from a 
TABLE 2. Number of King Eider ducklings observed in broods of radio-tracked females at Kuparuk, Alaska, 2002-2003. All females experienced complete brood loss within the first 2 weeks after hatch.

\begin{tabular}{ccccc}
\hline & \multicolumn{5}{c}{ Age (days) } \\
\cline { 2 - 5 } ID \# & Hatch & $1-5$ & $5-10$ & $10-15$ \\
\hline KIEI02 & 4 & 0 & & \\
KIEI06 & 5 & 3 & 0 & \\
KIEI17 & 3 & 0 & & \\
KIEI29 & 6 & 3 & 0 & \\
KIEI68 & 4 & 4 & 1 & 0 \\
KIEI70 & 5 & 5 & 1 & 0 \\
KIEI87 & 3 & 3 & 0 & \\
KIEI95 & 4 & 3 & 3 & 0 \\
\hline
\end{tabular}

tracked brood by a Glaucous Gull (Larus hyperboreus) and witnessed two unsuccessful attacks on radio-tracked broods, including one by two Parasitic Jaegers (Stercorarius parasiticus) and another by a Glaucous Gull.

Average daily movement rate of hens with broods was $507.4 \pm 68.7 \mathrm{~m} /$ day $(n=56$; range $=0-2,376 \mathrm{~m}$ ). Longer daily movement rates did not affect the number of days a brood survived $\left(F_{1,8}=0.10, P=0.76\right)$. Distance traveled per day by hens with broods did not vary with duckling age $\left(F_{1,54}=0.90, P=\right.$ 0.35 ). Hens did not appear to travel in a particular general direction with ducklings after hatch. Four hens moved east, three north, two south, and one west.

Crèche formation was not extensive; we rarely observed crèches of King Eiders on the study area and only observed two marked hens with broods in crèches. The hens that joined crèches were the only females in our study to successfully raise young to 30 days of age. One marked hen hatched five ducklings, but was later observed with three King and three Spectacled (S. fischeri) Eider chicks. We first observed her in a crèche when her chicks were 9 days of age. We later observed this hen in a crèche of up to 40 hens and 12 young. We believe some of these ducklings were still associated with the marked hen based on their behavior. We observed the second successful hen in a small crèche with one other hen when her chicks were 18 days of age; each had a brood of two ducklings. The two broods were discernable by their different ages with the marked hen having smaller, younger ducklings.

\section{DISCUSSION}

We offer the first description of survival of King Eider broods in Alaska. We observed lower apparent survival of broods (20\%) than observed for King Eiders breeding at Karrak Lake in Nunavut, Canada (35\%, Mehl and Alisauskas 2007). Apparent survival of King Eider broods at Kuparuk was also lower than reported for related eider species in Alaska. Half (49\%) of all Spectacled Eider (Flint and Grand 1997) and $73 \%$ of all Common Eider (S. mollissima) females (Flint et al. 1998) on the Yukon-Kuskokwim Delta lost their broods within 30 days of hatch.

Our calculation of apparent survival of broods does not include an estimate of variation in the data. Given our small sample size and probable variation among years, we would assume this variation to be significant. Mayfield estimates of survival for King Eider broods at Kuparuk, while low, show large confidence intervals that overlap with survival estimates for broods at Karrak Lake $(31 \%$, 95\% CI: 13-50\%; Mehl and Alisauskas 2007).

Gull predation has been identified as a primary cause of eider duckling mortality (Mendenhall and Milne 1985, Mehl and Alisauskas 2007). Glaucous Gulls nest across Alaska's Arctic Coastal Plain; studies have indicated their populations may be more concentrated near coastal villages and areas of industrial development such as Kuparuk and Prudhoe Bay (Noel et al. 2006). Other potential predators of ducklings at Kuparuk included Parasitic Jaeger, Common Raven (Corvus corax), and arctic fox (Alopex lagopus). The population of predators in Alaskan oil fields has increased since development, most likely due to greater access to food from anthropogenic sources such as landfills and garbage dumpsters, and shelter for nesting and denning sites (National Research Council 2003).

We did not observe extensive crèche formation at Kuparuk similar to Mehl and Alisauskas (2007) at Karrak Lake; however, the only hens in our study that successfully raised ducklings joined other females with broods. Crèche formation may increase duckling survival by females jointly caring for young and by larger brood sizes diluting the risk of predation (Eadie et al. 1988).

King Eider brood survival did not improve 
with greater distance travelled over land in the Kuparak area in contrast to the findings of Mehl and Alisauskas (2007) at Karrak Lake. We hypothesize the contrasting results of these two studies may be partially explained by habitat composition of the study areas. The Karrak Lake site is a large lake with many islands, while Kuparuk is characterized by small ponds and wetland complexes. Mehl and Alisauskas (2007) hypothesized that movement of broods to smaller ponds from the main nesting areas at Karrak Lake improved survival by providing better foraging, lower gull densities, and more shelter from winds. Movements from nesting locations at Kuparuk would not yield the same benefits because nesting already occurs on small ponds.

We had little evidence to suggest broods not re-observed with hens were adopted, because crèche formation was limited in the study area and we did not observe hens with an unusually large number of ducklings. Our analysis of brood survival underestimated mortality by censoring broods from the analysis that were not re-observed after hatch, but our observations of King Eider broods at Kuparuk suggest that survival of broods may be low. Our findings should be useful for developing a comprehensive investigation of King Eider survival as more King Eider nesting habitat across northern Alaska is leased for resource development. We encourage additional study of King Eider survival on the North Slope of Alaska especially near areas of resource development where survival of ducklings may be depressed by artificially inflated predator populations.

\section{ACKNOWLEDGMENTS}

Financial support for this research was provided by the Coastal Marine Institute and Minerals Management Service. Additional support was provided by ConocoPhillips, Alaska Inc., the North Slope Borough, U.S. Geological Survey, Alaska Cooperative Fish and Wildlife Research Unit, University of Alaska Foundation Angus Gavin grant, and the U.S. Fish and Wildlife Service. We acknowledge the valuable suggestions and assistance provided by Chuck Monnett, Jeff Gleason, Betty Anderson, Philip Martin, Catherine Rea, Anne Lazenby, Leigh McDaniel, Justin Harth, Robert Suydam, and Declan Troy. We thank Eric Duran, Lori Guildehaus, Ben Soiseth, and Rebecca Bentzen for field assistance. Carol McIntyre, Nora Rojek, and two anonymous reviewers provided helpful reviews of earlier drafts of the manuscript. Any use of trade, product, or firm names in this publication is for descriptive purposes only and does not imply endorsement by the U.S. Government.

\section{LITERATURE CITED}

Anderson, B. A., C. B. Johnson, B. A. Cooper, L. N. Smith, And A. A. Stickney. 1999. Habitat associations of nesting Spectacled Eiders on the Arctic Coastal Plain of Alaska. Pages 27-32 in Behavior and ecology of sea ducks (R. I. Goudie, M. R. Peterson, and G. J. Robertson, Editors). Occasional Paper Number 100. Canadian Wildlife Service, Ottawa, Ontario, Canada.

BACON, B. R. AND J. O. Evrard. 1990. Horizontal mist nets for capturing upland nesting ducks. North American Bird Bander 15:18-19.

Bergman, R. D., R. L. Howard, K. F. Abraham, And M. W. WELLER. 1977. Water birds and their wetland resources in relation to oil development at Storkersen Point, Alaska. Resource Publication 129. USDI, Fish and Wildlife Service, Washington D.C., USA.

Dickson, D. L., R. C. Cotter, J. E. Hines, and M. F. KAY. 1997. Distribution and abundance of King Eiders in the western Canadian arctic. Pages 2939 in King and Common eiders of the western Canadian arctic (D. L. Dickson, Editor). Occasional Paper Number 94. Canadian Wildlife Service, Ottawa, Ontario, Canada.

Dzus, E. H. AND R. G. Clark. 1997. Overland travel, food abundance, and wetland use by Mallards: relationships with offspring survival. Wilson Bulletin 109:504-515.

Eadie, J. M., F. P. Kehoe, And T. D. Nudds. 1988. Prehatch and post-hatch brood amalgamation in North American Anatidae: a review of hypotheses. Canadian Journal of Zoology 66:1709-1721.

ESRI. 1998. ArcView GIS Version 3.2. Environmental Research Institute Inc., Redlands, California, USA.

FLint, P. L. AND J. B. GRAND. 1997. Survival of Spectacled Eider adult females and ducklings during brood rearing. Journal of Wildlife Management 61: 217-221.

Flint, P. L., C. L. Moran, And J. L. Schamber. 1998. Survival of Common Eider Somateria mollissima adult females and ducklings during brood rearing. Wildfowl 49:103-109.

GiRARD, G. L. 1939. Notes on the life history of the Shoveler. Transactions of the North American Wildlife Conference 4:364-371.

Gratto-Trevor, C. L., V. H. Johnston, and S. T. PePPER. 1998. Changes in shorebird and eider abundance in the Rasmussen Lowlands, N. W. T. Wilson Bulletin 110:316-325.

Hooge, P. N. And B. Eichenlaub. 1997. Animal movement extension to ArcView. Version 1.1. USDI, Geological Survey, Alaska Science Center, Anchorage, USA. http://www.absc.usgs.gov/glba/gistools (accessed 30 January 2005).

JoHnson, D. H. 1979. Estimating nest success: the Mayfield method and an alternative. Auk 96:651-661. 
Johnson, D. H., J. D. Nichols, And M. D. SchwaRtz. 1992. Population dynamics of breeding waterfowl. Pages 446-475 in Ecology and management of breeding waterfowl (B. D. J. Batt, A. D. Afton, M. G. Anderson, C. D. Ankney, D. H. Johnson, J. A. Kadlec, and G. L. Krapu, Editors). University of Minnesota Press, Minneapolis, USA.

MAYFIELD, H. F. 1961. Nesting success calculated from exposure. Wilson Bulletin 73:255-261.

MAYFIELD, H. F. 1975. Suggestions for calculating nest success. Wilson Bulletin. 87:456-466.

Mehl, K. R. and R. T. Alisauskas. 2007. King Eider (Somateria spectabilis) brood ecology: correlates of duckling survival. Auk 124:606-618.

Mendenhall, V. M. AND H. Milne. 1985. Factors affecting duckling survival of eiders Somateria mollissima in northeast Scotland. Ibis 127:148-158.

National Research Council. 2003. Cumulative environmental effects of oil and gas activities on Alaska's North Slope. National Academies Press, Washington D.C., USA.

Noel, L. E., S. R. Johnson, And W. J. Gazey. 2006. Oilfield development and Glaucous Gull (Larus hyperboreus) distribution and abundance in central Alaskan Beaufort Sea lagoons, 1970-2001. Arctic 59:65-78.

Pietz, P. J., D. A. Brandt, G. L. Krapu, and D. A. BuHL. 1995. Modified transmitter attachment method for adult ducks. Journal of Field Ornithology 66:408-417.
Rotella, J. J. AND J. T. Ratti. 1992. Mallard brood movements and wetland selection in southwestern Manitoba. Journal of Wildlife Management 56: 508-515.

SAS INSTITUTE. 1990. SAS user's guide: statistics. Version 8. SAS Institute Inc., Cary, North Carolina, USA.

SAYLER, J. W. 1962. A bow-net trap for ducks. Journal of Wildlife Management 26:219-221.

Seymore, N. AND W. JACKSON. 1996. Habitat-related variation in movements and fledging success of American Black Duck broods in northeastern Nova Scotia. Canadian Journal of Zoology 74: $1158-1164$.

Suydam, R. S. 2000. King Eider (Somateria spectabilis). The birds of North America. Number 491.

Suydam, R. S., D. L. Dickson, J. B. FAdely, AND L. T. Quakenbush. 2000. Population declines of King and Common eiders of the Beaufort Sea. Condor 102:219-222.

WaYland, M. AND D. K. MCNicol. 1994. Movements and survival of Common Goldeneye broods near Sudbury, Ontario, Canada. Canadian Journal of Zoology 72:1252-1259.

Weller, M. W. 1956. A simple field candler for waterfowl eggs. Journal of Wildlife Management 20: 111-113.

YERKES, T. 2000. Influence of female age and body condition on brood and duckling survival, number of surviving ducklings, and brood movements in Redheads. Condor 102:926-929.

\title{
Diet Composition of Wintering Wilson's Snipe
}

\author{
Jon T. McCloskey, ${ }^{1,2}$ Jonathan E. Thompson, ${ }^{1,3}$ and Bart M. Ballard ${ }^{1,4}$
}

ABSTRACT.-We examined diet composition of Wilson's Snipe (Gallinago delicata) $(n=372)$ collected along the central Gulf Coast of Texas based solely on upper digestive tract contents. Food items included 11 invertebrate orders, one invertebrate class, and eight plant genera. Oligochaetes were the predominant food throughout the non-breeding period, but snipe consumed fewer $(P=0.021)$ earthworms in spring than in fall. Aquatic insects were frequently

${ }^{1}$ Caesar Kleberg Wildlife Research Institute, MSC 218, Texas A\&M University-Kingsville, Kingsville, TX 78363, USA.

${ }^{2}$ Current address: BioDiversity Research Institute, 19 Flaggy Meadow Road, Gorham, ME 04038, USA.

${ }^{3}$ Current address: Ducks Unlimited Canada, \#200, 10720-178 Street, Edmonton, AB T5S 1J3, Canada.

${ }^{4}$ Corresponding author; e-mail:

bart.ballard@tamuk.edu consumed by snipe and during spring represented approximately the same proportion of the diet as earthworms. Plant foods consisted almost entirely of seeds and comprised $9.7-26.8 \%$ of the diet throughout the non-breeding period. Wilson's Snipe consumed dipteran larvae more often during spring than fall $(P=$ 0.056). Female snipe consumed crustaceans during spring $(14.8 \%)$, while only trace amounts were found in the diet of male snipe. Differences in the diet of Wilson's Snipe between males and females were probably related to differences in habitat use as well as availability of invertebrates throughout the non-breeding period. Received 5 March 2008. Accepted 7 September 2008.

Studies of Wilson's Snipe (Gallinago delicata) suggest that animal foods are a signifi- 
cant portion of their winter diet (Erickson 1941, Whitehead 1965, White and Harris 1966, Owens 1967, Booth 1968, Jirovec 1971, Tuck 1972). Most studies suggest aquatic insects and mollusks are the primary animal foods consumed by snipe and discount the importance of earthworms (Oligochaeta). Owens (1967) found earthworms in 50\% of the birds he collected in wet cattle pastures in Louisiana, but they accounted for only $21.6 \%$ of the total animal volume in the diet. Previous studies stimulated debate over the importance of plant foods in the diet of wintering Wilson's Snipe. Whitehead (1965), Owens (1967), and Booth (1968) found the dry mass of plant materials comprised $\sim 41,50$, and $62 \%$ of the diet of wintering snipe, respectively. In contrast, White and Harris (1966) and Jirovec (1971) reported that plant foods accounted for $\leq 20 \%$ of the dry mass in the diet.

Inconsistencies between these studies and the conclusion that earthworms are relatively unimportant in the diet of wintering snipe probably occurred because they included gizzard contents in diet composition analysis. This approach biases diet composition toward hard food items (i.e., plant foods or hard animal parts) because the grinding action of the gizzard quickly renders soft foods (e.g., earthworms) unrecognizable (Rundle 1982). This bias can be avoided by examining only the contents of the esophagus and proventriculus (Swanson and Bartonek 1970, Reinecke and Owen 1980, Rundle 1982).

Snipe have long bills with a prehensile tip used to probe moist soils in search of invertebrates (Arnold 1994). Winter habitats used by Wilson's Snipe typically have wet ground (i.e., wet pastures, plowed and fallow rice fields, and coastal marshes) (Arnold 1994), and soil moisture is a primary variable regulating earthworm abundance and distribution (Curry 1998). Our objective was to quantify the diet of wintering Wilson's Snipe based solely on examination of upper digestive tract contents.

\section{METHODS}

We conducted this study in the rice prairies and coastal marshes along the central Gulf Coast of Texas from October 1997 through April 1998. Collection sites included five different habitat types: harvested rice fields, fal- low rice fields, mud flats (i.e., recently disked fallow rice fields), drained impoundments, and coastal marshes. Vegetation communities and land use practices associated with the study area were described by McCloskey (1999).

We collected Wilson's Snipe $(n=372)$ by shooting, systematically alternating between habitat types throughout the non-breeding period. We typically collected four birds per day allocated throughout the day. We examined diet composition by analyzing the contents of the upper digestive tract (UDT) (i.e., esophagus and proventriculus). Each specimen was injected with $2-3 \mathrm{ml}$ of $80 \%$ ethanol into their UDT immediately after collection to prevent post-mortem digestion of food items. The UDT contents were subsequently placed into individually labeled nalgene bottles containing $80 \%$ ethanol (Swanson and Bartonek 1970). Food items were sorted, classified, and dried to constant mass at $80^{\circ} \mathrm{C}$ to quantify percent occurrence and aggregate percent dry mass of foods consumed during each season. We separated the non-breeding period into three seasons based on molt intensity of collected individuals. A fall molting period was delineated as 6 October-13 November 1997, a non-molting winter period was delineated as 14 November 1997-4 February 1998, and a spring molting period was 5 February-10 April 1998.

We used Kruskal-Wallis one-way ANOVA (PROC NPAR1WAY; SAS Institute Inc. 1999) to investigate seasonal variation in diet of males and females. We used Dunn's Multiple Comparisons Test (SAS Institute Inc. 1999) to examine any seasonal differences. We used Mann-Whitney $U$-tests to compare diets between males and females within each season.

\section{RESULTS}

Sixteen of 39 females and 16 of 30 males contained food in their upper digestive tract during fall. Only 19 of 95 females and 11 of 64 males contained food in their UDT in winter. The proportion of birds with ingesta increased in spring with 26 of 86 females and 17 of 58 males containing food in their UDT. Proportions of male and female snipe containing food were highest throughout spring migration (16 Mar-10 Apr), with 21 of 41 females and 11 of 17 males containing food in 
their UDT. Diets of Wilson's Snipe included foods from 11 invertebrate families, one invertebrate class, one vertebrate species, and eight plant genera (Table 1). Snipe fed primarily on animal foods, which represented $>73 \%$ of the dry mass of the diet throughout the non-breeding period (Table 1). Ninety-one percent of all snipe that contained food in their UDT consumed animal foods.

Oligochaetes (earthworms) were the primary food item of Wilson's Snipe, representing from 33.1 to $67.3 \%$ of the dry mass of the diet over the entire non-breeding period (Table 1). There were seasonal differences in Oligochaete consumption $(H=6.08, \mathrm{df}=2, P=0.048)$. The diet of male and female snipe contained similar proportions of Oligochaetes during fall and spring but, during winter, earthworms comprised $63.4 \%$ of the total food mass of males, compared to only $38.3 \%$ for females (Table 1). Oligochaetes comprised a greater proportion of the diet of both males and females during fall than during spring $(P=0.021)$.

Aquatic insects represented $12.4-35 \%$ of the diet of male and female Wilson's Snipe. Coleoptera (i.e., Hydrophilidae larvae and unidentified adult parts), Diptera larvae (i.e., Ceratopogonidae, Chironomidae, Culicidae, and Tipulidae), and Hemiptera were the most frequently eaten aquatic insects by male and female snipe (Table 1). There were seasonal differences in the amount of aquatic insects consumed $(H=10.96$, df $=2, P=0.004)$, with both males and females increasing their consumption during spring. The combined dry mass of Coleoptera, Diptera, and Ephemeroptera in spring represented $33 \%$ of the diet for females and $35 \%$ for males, which approximated the dry mass of Oligochaetes in the diet during this period (Table 1). Male and female snipe consumed dipteran larvae most often during spring $(P=0.056)$.

Crustaceans were ingested almost exclusively by female snipe with males consuming only trace amounts (i.e., $<1 \%$ ) of isopods during winter and spring (Table 1). Females consumed amphipods and isopods only during winter and spring (Table 1). We found no crustaceans in the UDT of any individuals during fall, and females ate decopods only during spring (Table 1).

The remaining animal foods consisted of Arachnoidea (i.e., Hydracarina), mollusks (i.e., Gastropoda and Pelecypoda), one southern cricket frog (Acris gryllus gryllus), and unidentified invertebrate parts (Table 1). Only females consumed Hydracarina with the majority being consumed during fall and winter. Females consumed mollusks during all seasons, while males consumed gastropods and pelecypods mostly during spring (Table 1).

Plant foods represented $\leq 26.8 \%$ of the diet and were detected in $\leq 62.5 \%$ of male and female Wilson's Snipe throughout the non-breeding period (Table 1). Seeds, particularly those of Cyperus spp., Eleocharis spp., and Polygonum spp. were the most frequently consumed plant foods (Table 1). Polygonum spp. was consumed almost exclusively by females and mostly during fall and winter $(H=7.534$, df $=2, P=$ 0.023). Male snipe consumed only trace amounts of Polygonum and only during fall (Table 1). Plant parts (i.e., stems and leaves) were not considered food items because they usually comprised only a trace of the total plant dry mass (Table 1), and were typically found in association with other food items suggesting they were picked up incidentally.

\section{DISCUSSION}

The proportion of Wilson's Snipe containing ingesta in their UDT was greatest during fall and spring. These periods coincide with molting, and protein demand may be greater for snipe during these periods (Ankney 1979, Murphy and King 1982). Spring migration occurred between 16 March and 10 April (McCloskey 1999), and aggregate percent dry mass of animal foods was greatest during this time suggesting snipe were storing lipid reserves for migration. Much of the southern portion of the snipe's winter range in the United States is characterized by wet, but relatively warm weather, which results in continuous periods of invertebrate reproduction and growth (Merritt and Cummins 1996). If food is readily available and energy requirements for thermoregulation are relatively low in winter, snipe may alter their foraging strategy to specific times of the day or night. This may partially explain the lower proportion of our sample that contained ingesta in their UDT during winter.

Female snipe consumed a wider variety of invertebrates than males during winter with crustaceans, mollusks, and arachnids compris- 
SHORT COMMUNICATIONS

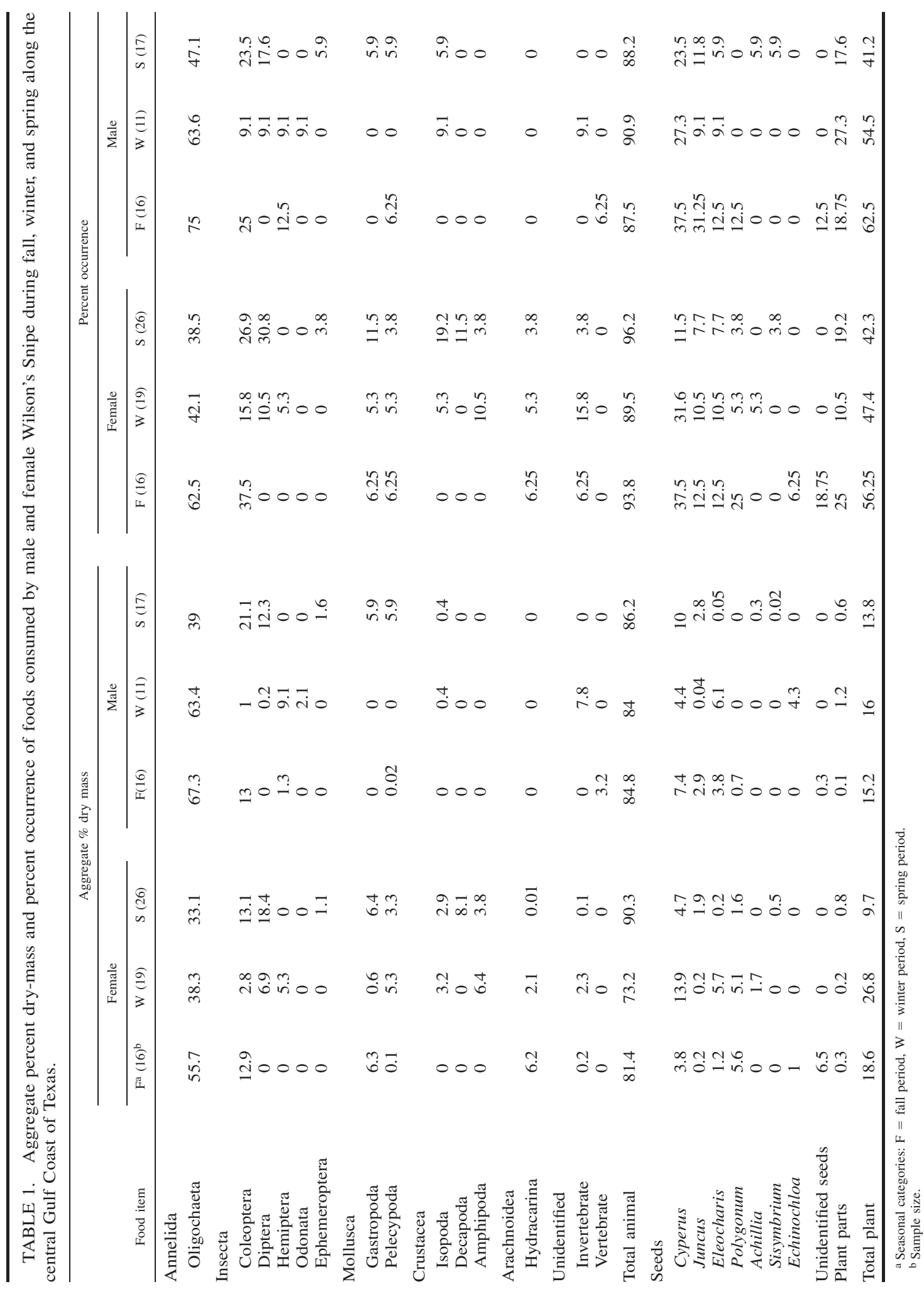


ing $9.6,5.9$, and $2.1 \%$ of their diet, respectively. These food items were essentially absent from the diet of males during winter. These apparent differences in invertebrate use between male and female Wilson's Snipe during winter may be related to differential partitioning of winter habitats (McCloskey and Thompson 2000).

Fall rains flood marshes and probably benefit earthworms initially, which may explain why earthworms were more common in the diet of snipe during fall. However, continued flooding and subsequent drying of soils can increase salinity levels, which can limit earthworm populations (Curry 1998). While earthworms were the predominant food of snipe during fall and winter, aquatic insects became equally important in their diet during spring. Emergence of aquatic insects is synchronized primarily by water availability, temperature, and oxygen levels (Merritt and Cummins 1996), and may explain their increased ingestion during spring. Increased availability of aquatic insects may allow snipe to obtain nutrient stores required for spring migration without expending as much energy.

Previous studies on the diet of wintering Wilson's Snipe reported high frequency of occurrence of seeds, but most discounted their importance suggesting seeds were ingested incidentally while probing for invertebrates (Erickson 1941, Whitehead 1965, White and Harris 1966, Owens 1967, Booth 1968, Jirovec 1971, Tuck 1972). Fritzell et al. (1979) also discounted the importance of seeds, suggesting they were ingested incidentally, remained relatively unchanged during digestion, or would eventually be regurgitated. However, we found UDT contents of nine snipe to be comprised solely of seeds. Booth (1968) found over 45,000 seeds of 48 plant species in gizzards of 260 wintering snipe collected in Louisiana. Although animal foods clearly dominate the diet of wintering snipe, seeds may be an important source of carbohydrates and may be more than just incidentally consumed.

Wintering Wilson's Snipe consume a variety of plant and animal foods during the nonbreeding period. Snipe spend $\sim 8$ months of the year in wintering areas and the diversity of food types in these areas provide them with energy required for basal metabolic requirements, daily activity, molt, thermoregulation during cold spells, and migration in spring. Snipe use a variety of habitats on wintering areas that are both permanent and ephemeral in nature (Arnold 1994), which can affect the distribution and abundance of invertebrates throughout the non-breeding period. Thus, snipe need a diversity of habitat types in wintering areas. These habitats should contain moist soils and provide a diversity of plant and animal foods. The ability to identify and maintain potential snipe habitat will become increasingly important with continuing wetland loss along the Gulf Coast of Texas (Moulton et al. 1997).

\section{ACKNOWLEDGMENTS}

The 1997 Webless Migratory Game Bird Research Program (USDI, Fish and Wildlife Service and Geological Survey-Biological Resources Division) and the Caesar Kleberg Wildlife Research Institute provided funding for this project. We thank Jeff Stephens for help in collecting and processing birds. We also thank Keith Treybig for access to El Rancho de los Patos and Rick Spears, Rick Antonette, and Ron Bisbee for access to Brazoria National Wildlife Refuge. We also thank Todd Merendino, Justin Hurst, Ernest Love, and Brent Ortego for access to Texas Wildlife Management Areas. We thank personnel at Attwater's Prairie Chicken National Wildlife Refuge for providing housing and hospitality. This is publication Number 99-116 from the Caesar Kleberg Wildlife Research Institute.

\section{LITERATURE CITED}

AnKNEY, C. D. 1979. Does the wing molt cause nutritional stress in Lesser Snow Geese? Auk 96:6872.

Arnold, K. A. 1994. Common Snipe. Pages 116-125 in Migratory shore and upland game bird management in North America (T. C. Tacha and C. E. Braun, Editors). International Association of Fish and Wildlife Agencies, Washington, D.C., USA.

Bоотн JR., T. W. 1968. The availability and utilization of the foods of the Common Snipe (Capella gallinago delicata) in the rice growing region of southwestern Louisiana. Thesis. Louisiana State University, Baton Rouge, USA.

CurRy, J. P. 1998. Factors affecting earthworm abundance in soils. Pages 37-64 in Earthworm ecology (C. A. Edwards, Editor). St. Lucie Press, Boca Raton, Florida, USA.

ERICKSON, A. V. 1941. A study of the Wilson's Snipe. Wilson Bulletin 53:62.

Fritzell, E. K., G. A. Swanson, and M. I. Meyer. 1979. Fall foods of migrant Common Snipe in North Dakota. Journal of Wildlife Management 43:253-257.

JIROVEC, D. J. 1971. Food habits and migratory movements of the Common Snipe (Capella gallinago 
delicata) in the central Brazos Valley of Texas. Thesis. Texas A\&M University, College Station, USA.

McCloskey, J. T. 1999. Sex and age determination and nutritional ecology of wintering Common Snipe. Thesis. Texas A\&M University-Kingsville, Kingsville, USA.

McCloskey, J. T. And J. E. Thompson. 2000. Sexrelated differences in migration chronology and winter habitat use of Common Snipe. Wilson Bulletin 112:143-148.

Merritt, R. W. AND K. W. Cummins. 1996. An introduction to the aquatic insects of North America. Kendall/Hunt Publishing Co., Dubuque, Iowa, USA.

Moulton, D. W., T. E. Dahl, And D. M. Dall. 1997. Texas coastal wetlands; status and trends, mid1950 s to early 1990s. USDI, Fish and Wildlife Service, Albuquerque, New Mexico, USA.

Murphy, M. E. AND J. R. King. 1982. Amino acid composition of the plumage of the White-crowned Sparrow. Condor 84:435-438.

Owens, J. 1967. Food habits of the Common Snipe (Capella gallinago delicata) in the pastures of south central Louisiana. Thesis. Northeast Louisiana State College, Monroe, USA.
Reinecke, K. J. And R. B. Owen JR. 1980. Food use and nutrition of Black Ducks nesting in Maine. Journal of Wildlife Management 44:549-558.

RundLE, W. D. 1982. A case for esophageal analysis in shorebird food studies. Journal of Field Ornithology 53:249-257.

SAS InStitute Inc. 1999. SAS/STAT user's guide. Version 8. SAS Institute Inc., Cary, North Carolina, USA.

Swanson, G. A. And J. C. Bartonek. 1970. Bias associated with food analysis in gizzards of Bluewinged Teal. Journal of Wildlife Management 34: 739-746.

Tuck, L. M. 1972. The snipes: a study of the genus Capella. Monograph Series 5. Canadian Wildlife Service, Ottawa, Ontario, Canada.

White, M. AND S. HARRIS. 1966. Winter occurrence, foods, and habitat use of snipe in northwest California. Journal of Wildlife Management 30:2334

WhiteHEAd, C. J. 1965. Foods and feeding habits of the Common Snipe (Capella gallinago delicata) in Cameron Parish, Louisiana, with ecological notes and a discussion of methods of sexing and aging. Thesis. Louisiana State University, Baton Rouge, USA.

\title{
An Overlooked Cost for the Velvety Plumage of Owls: Entanglement in Adhesive Vegetation
}

\author{
Airam Rodríguez, ${ }^{1,5}$ Felipe Siverio, ${ }^{2}$ Rubén Barone, ${ }^{3}$ Beneharo Rodríguez, ${ }^{4}$ \\ and Juan J. Negro ${ }^{1}$
}

ABSTRACT.-We used data collected during 19952007 at the only Wildlife Rehabilitation Center on Tenerife Island (Canary Islands) to quantify entanglement mortality of owls. At least 66 of 1,206 Longeared (Asio otus) and 5 of 231 Barn (Tyto alba) owls admitted to the Wildlife Rehabilitation Center were entangled in burr bristlegrass (Setaria adhaerens). Twelve $(18.2 \%)$ of the 66 Long-eared Owls died as a result of entanglement while one of five Barn Owls

\footnotetext{
${ }^{1}$ Estación Biológica de Doñana (CSIC), Avenido Américo Vespucio s/n, 41092 Sevilla, Spain.

${ }^{2}$ Los Barros 21, 38410 Los Realejos, Tenerife, Canary Islands, Spain.

${ }^{3} \mathrm{C} /$ Eduardo Zamacois $13-3^{\circ} \mathrm{A}, 38005$ Santa Cruz de, Tenerife, Canary Islands, Spain.

${ }^{4}$ C/ La Malecita s/n, 38480 Buenavista del Norte, Tenerife, Canary Islands, Spain.

${ }^{5}$ Corresponding author; e-mail: airamrguez@ebd.csic.es
}

died. A higher incidence of entanglement occurred during summer, coinciding with seed-head ripening and dispersing recently-fledged owls. Velvety plumage may be an important cost for owls, and responsible for owls acting as seed dispersers. Received 28 June 2008. Accepted 14 December 2008.

Owls have evolved adaptations to hunt in poor light conditions, including frontally located and disproportionately large eyes or, in some species, an asymmetrical placement of the ear openings for improved hearing (del Hoyo et al. 1999). Owls also have feathers with traits which have been considered as adaptations for silent flight. The main structural feather adaptations of owls are: (1) elongated barbs on the leading edge at the outer prima- 
ries, (2) a trailing edge on the flight feathers, and (3) modified distal barbules on the dorsal surface of feathers (del Hoyo et al. 1999). The last trait makes velvety plumage easily perceived by the unaided human eye (Mikkola 1983). This plumage is also exhibited by other nocturnal or crepuscular birds, including nightjars (Order Caprimulgiformes), Bat Hawk (Macheiramphus alcinus) (J. J. Negro, pers. obs.), and Elanus kites (Negro et al. 2006). Silent flight permits owls to go undetected by their prey, and improves their ability to detect noises (Taylor 1994, del Hoyo et al. 1999).

Development of velvety plumage may have associated costs, including increased risk of entanglement in dense vegetation during hunting (Glayre 1959, Mendelsohn 1983, Nozerand 1994, Molnar 1996). We describe mortality, caused by a grass species, of the resident owl community in the Canary Islands. Only two species of owls regularly breed in the Canary Islands: Long-eared Owl (Asio otus) and Barn Owl (Tyto alba).

Burr bristlegrass (Setaria adhaerens, Family Poaceae) is an annual species, possibly native in the Canary Islands (Izquierdo et al. 2004). It grows in orchards, abandoned farmlands, road ditches, and field margins. It flowers and dries during spring and early summer, and retains ripe seed-heads in the dry plant (R. Mesa, pers. comm.). Ripe seed-heads are adhesive and adapted to exozoocore dispersal.

\section{OBSERVATIONS}

Owls admitted during 1995-2007 were identified by the staff of the Wildlife Rehabilitation Center "La Tahonilla", (WRC), which annotated recovery circumstances. The center is in Tenerife, the largest island $(2,034$ $\mathrm{km}^{2}$ and $3,718 \mathrm{~m}$ of altitude) of the Canarian archipelago $\left(27^{\circ} 37^{\prime}-29^{\circ} 24^{\prime} \mathrm{N}, 13^{\circ} 20^{\prime}-18^{\circ}\right.$ $8^{\prime} \mathrm{W}$ ), and our data correspond to owls found only on this island.

At least $66(5.5 \%)$ of 1,206 Long-eared and $5(2.2 \%)$ of 231 Barn owls admitted were entangled in S. adhaerens plants. Entanglement in burr bristlegrass likely occurred when owls were hunting. Twelve of 66 Long-eared Owls (18.2\%) and one of five Barn Owls died as a result of becoming entangled in the plants. Most entangled birds that were recovered alive would have died if not found because owls do not appear capable of freeing themselves from the plant. The highest incidence of entanglements occurred during summer with the largest number of reports in July and August.

\section{DISCUSSION}

The interaction between owls and a plant adapted to exozoocore dispersal can be a considerable cause of mortality in the Canary Islands. This factor has been overlooked, despite several published records, and has not been quantified in the literature. Entanglement of owls in vegetation appears to be the result of anthropogenic perturbations in the Canary Islands, even though $S$. adhaerens is possibly a native plant (Izquierdo et al. 2004). Burr bristlegrass is mainly associated with humanaffected landscapes and is almost absent in natural areas. The highest densities of $S$. adhaerens are in human-transformed areas, which is where owls tend to become entangled. The temporal pattern with maximum values during the summer, may be related to ripening of seed-heads, as well as to dispersal of fledgling owls (age of affected owls is not available).

Entanglement of birds with velvety plumages has been reported involving Long-eared Owls, Barn Owls, and Black-winged Kites (Elanus caeruleus) (Glayre 1959, Mendelsohn 1983, Nozerand 1994, Molnar 1996). Entanglement as a cause of mortality is not exclusive to birds with velvety plumages. At least two instances involving Common Kestrels (Falco tinnunculus) entangled in S. adhaerens in the Canary Islands are known (WRC, unpubl. data; J. Curbelo, pers. comm.). The Common Kestrel is the most abundant raptor in the Canary Islands, and >1,200 have been admitted to the WRC in the study period. Whether Common Kestrels become entangled less often than owls due to different plumage characteristics or due to different micro-habitat use remains unknown.

It is possible that some owls escape unscathed from contact with $S$. adhaerens, but seeds of this species may become affixed to their plumage and transported elsewhere. This interaction implies a new ecological role for owls as exozoocore seed dispersers. 


\section{ACKNOWLEDGMENTS}

We are grateful to those who helped rescuing owls and the staff of Wildlife Rehabilitation Center " $\mathrm{LaTa}$ honilla" (Cabildo Insular de Tenerife). Ricardo Mesa, Juani Curbelo, and Rubén García provided valuable information about the genus Setaria and entanglement observations. G. R. Bortolotti, J. S. Marks, an anonymous reviewer, and C. E. Braun provided useful comments on an early draft of the manuscript.

\section{LITERATURE CITED}

del Hoyo, J., A. Elliott, and J. Sargatal (Editors). 1999. Handbook of the birds of the world. Volume 5. Barn-owls to hummingbirds. Lynx Editions, Barcelona, Spain.

Glayre, D. 1959. Une Choutte effraie capturée pas des graminées. Nos Oiseaux 266:122.

IzQuierdo, I., J. L. Martín, N. ZuRita, AND M. AREChavaleta. 2004. Lista de Especies Silvestres de
Canarias (Hongos, Plantas y Animales Terrestres). Consejería de Medio Ambiente y Ordenación Territorial, Gobierno de Canarias, Santa Cruz de Tenerife, Spain.

Mendelsohn, J. M. 1983. Causes of mortality in Black-shouldered Kites. Bokmakierie 35:11-13.

Mikкola, H. 1983. Owls of Europe. T. \& A.D. Poyser, London, United Kingdom.

MolnAR, G. 1996. Ragados muhar (Setaria verticillata) mint bagolycsapda. Tuzok 1:185.

Negro, J. J., C. Pertoldi, E. Randi, J. J. Ferrero, J. M. LÓPEZ-CABAllero, D. Rivera, AND E. KorPIMÄKI. 2006. Convergent evolution of Elanus kite and the owls. Journal of Raptor Research 40:222225.

Nozerand, R. 1994. Hiboux Moyens-Ducs Asio otus emprisonnés dans des graminées. Alauda 62:116.

TAYlOR, I. 1994. Barn Owls. Predator-prey relationships and conservation. Cambridge University Press, Cambridge, United Kingdom.

\title{
Aggressive Response of Adult Bobolinks to Neck Ligatures on Nestlings
}

\author{
Lynn P. Little, ${ }^{1,2}$ Allan M. Strong, ${ }^{3,5}$ and Noah G. Perlut ${ }^{4}$
}

\begin{abstract}
We monitored provisioning behavior at 18 Bobolink (Dolichonyx oryzivorus) nests during $240.5 \mathrm{~min}$ of videotape data from June to July 2006, and observed 64 nest visits by adults while nestlings were fitted with neck ligatures. Adults pecked or pulled at the ligatures, often aggressively, at $72 \%$ of nests $(n=18)$ and $52 \%$ of visits $(n=64)$. These behavioral responses by adults indicate the neck ligature technique is more invasive than previously believed. We documented no mortality as a result of ligature placement, but researchers should minimize the time that ligatures are in place to reduce stress to both parents and nestlings. Received 8 September 2008. Accepted 30 January 2009.
\end{abstract}

\footnotetext{
${ }^{1}$ Department of Animal Science, University of Vermont, Burlington, VT 05405, USA.

${ }^{2}$ Current address: 5060 Bentley Lane, Columbus, OH 43220, USA

${ }^{3}$ Rubenstein School of Environment and Natural Resources, 81 Carrigan Drive, University of Vermont, Burlington, VT 05405, USA.

${ }^{4}$ Vermont Cooperative Fish and Wildlife Research Unit, The Rubenstein School of Environment and Natural Resources, University of Vermont, Burlington, VT 05405, USA.

${ }^{5}$ Corresponding author; e-mail: allan.strong@uvm.edu
}

Quantitative assessments of avian diets may be critical for evaluating habitat quality. However, methods used to quantify avian diets have associated biases and/or shortcomings as most studies require techniques tailored to specific studies and hypotheses (Rosenberg and Cooper 1990). Neck ligatures have been used to quantify diets of nestling birds as this technique allows collection of prey items prior to onset of digestion. Modifications have been suggested to improve ligature function and minimize negative effects on nestlings. For example, Johnson et al. (1980) described abnormal behavior of nestlings after leaving ligatures in place for $1 \mathrm{hr}$ and suggested that collection of prey immediately after each parental visit would minimize biases. Further, Mellott and Woods (1993) found that cable ties simplified ligature placement compared to coated wire, especially when used by untrained personnel.

Neck ligatures are considered an invasive technique (Rosenberg and Cooper 1990, Poulsen and Aebischer 1995), but most studies addressing their effects have focused on the be- 
havioral responses of nestlings. We used video cameras and neck ligatures simultaneously in a study of nestling Bobolink (Dolichonyx oryzivorus) diets. We report on the response of adult Bobolinks to placement of neck ligatures on nestlings.

\section{METHODS}

Study Site.-Our study was conducted during June-July 2006 in three hayfields in Hinesburg, Shelburne, and Charlotte, Chittenden County, Vermont, USA. Bobolinks breed in hayfields and pastures throughout this agricultural region (Shustack 2004, Perlut et al. 2006) and their ground nests are relatively easy to locate.

Video and Ligature Data Collection.-Nest observations, video monitoring, and ligature sampling occurred between 0400 and $1300 \mathrm{hrs}$ EST during precipitation-free periods. A small, wide-angle "lipstick" lens (www. helmetcamera.com) was mounted $10 \mathrm{~cm}$ from the nest when nestlings reached 6 days of age. The lens was attached by cable to an $8-\mathrm{mm}$ camcorder (Sony DCR-TRV460 Digital8 Handycam) placed $2 \mathrm{~m}$ from the nest and concealed by vegetation. Recording sessions commenced with an initial 45-min acclimation period during which nestlings were left undisturbed. Recording was paused while neck ligatures were placed on nestlings following Johnson et al. (1980) and subsequent modifications (Mellott and Woods 1993). We placed ligatures on a maximum of three nestlings per nest using plastic cable ties $(10 \mathrm{~cm}$ length before cutting off excess, $2.5 \mathrm{~mm}$ width), temporarily removing any additional nestlings for the remainder of the videotaping period (generally $45 \mathrm{~min}$ ). Removal of some of the nestlings reduced the number of nestlings that were not fed by parents during a feeding session (adults were not observed feeding all nestlings in a single feeding trip when a nest contained five or six nestlings; N. G. Perlut, unpubl. data) and reduced the number of nestlings that would be exposed to any potential stress during the ligature process. We attempted to remove ligatures and collect diet samples from the nestlings as soon as we observed the adults return to the nest with food. Prolonged use of ligatures can induce abnormal swallowing and gaping behavior in nestlings, which leads to the redistribution of prey items among nestlings by adults (Johnson et al. 1980).

\section{RESULTS}

We monitored 18 Bobolink nests during 240.5 min of videotape data. We applied neck ligatures to 50 nestlings, and successfully collected 99 prey items from 28 of those nestlings. No nestling mortality occurred while nests were videotaped. Leaf hoppers $(27.3 \%$ based on numerical abundance), holometabolous larvae $(24.2 \%)$, grasshoppers (16.2\%), mayflies $(8.1 \%)$, spiders $(7.1 \%)$, and moths $(5.1 \%)$ were the most common prey types fed to nestlings. Mean \pm SD prey length was 14.5 $\pm 10.2 \mathrm{~mm}$ with $17 \%$ of prey items delivered $>25 \mathrm{~mm}$. Sixteen of the 18 nests were successful with 56 nestlings fledged.

We observed 64 nest visits by adults while nestlings were fitted with ligatures. Seventytwo percent of visits were by females and $28 \%$ by males. On average, females and males visited nests 2.6 and 1.0 times, respectively while ligatures were in place ( $\sim 45 \mathrm{~min}$ ). Adults pecked at ligatures of nestlings in 13 of 18 nests $(72 \%)$ and in 33 of $64(52 \%)$ visits. They directed pecks at more than one nestling in $70 \%$ of the visits during which adults pecked at the ligatures. Females had a greater propensity to peck at ligatures with $59 \%$ of all female visits eliciting pecks to ligatures compared to $33 \%$ of all male visits. The first adult to return to the nest pecked at the ligatures in 12 of 13 nests in which adults pecked at ligatures. There was no indication that probability of pecking changed across the time period ligatures were in place (logisitic regression, $\chi^{2}$ $=1.68, \mathrm{df}=1, P=0.20$ ).

Adults generally pecked at the thin band of the cable tie. In these cases, the adults appeared to be assessing whether or not the ligature could be easily removed from the chicks. Adults also grasped and pulled at the bulkier locking mechanism of the cable tie with the appearance that removal was the goal. Parents were notably aggressive in about half of the nests in their attempts to remove the ligatures, grasping the ligature and forcibly pulling the nestlings' heads upwards or sideways. In one instance, a female inspected, grasped, and pulled at a nestling's ligature for $30 \mathrm{sec}$. No aggressive actions toward nestlings were noted when ligatures were not present 
on nestlings based on video data prior to ligature placement and a few tapes which we left running after the ligature sessions. One female visually inspected her nestling's throats upon her first visit to the nest $\sim 20 \mathrm{~min}$ after removal of the ligatures.

\section{DISCUSSION}

Use of neck ligatures has been shown to provide quality dietary data for nestling birds (Orians 1966, Martin et al. 2000, Clotfelter et al. 2007). Our data support these results as we were able to collect a relatively large sample of prey items over a short period of time. Prey length data suggest that adults did not adjust the size of prey items brought to nestlings with ligatures. However, we do not have adequate control data (nestlings without ligatures) for a quantitative comparison.

Our data show that undesirable behavioral responses to ligatures are not restricted to nestlings. The strong and consistent response of adults to ligatures suggests this technique elicits stress that was not previously documented. Attempts by female Red-winged Blackbirds (Agelaius phoeniceus) to remove pipe cleaner ligatures have been documented, but no behavioral data were provided (Robertson 1966). Our results indicate that Bobolinks are strongly attuned to the appearance of their nestlings and, in most cases, neck ligatures trigger a response upon the first visit to the nest. Females in our sample were more likely to attempt to remove ligatures than males (but also made more nest visits). Approximately half of the attempts to remove the ligatures were aggressive with parents lifting and/or dragging nestlings by the ligature. These responses indicate the neck ligature technique is more invasive than previously believed. Comparable data from other species would be useful to better address the generality of our findings.

Gaunt and Oring (1999) noted the potential for changes in blood circulation, tracheal function, and food delivery rates with use of neck ligatures. Our data suggest there may be additional stress to nestlings beyond physical placement of the ligatures. The majority of nest visits by adults included pecking or pulling at neck ligatures and there was no indication that adults became habituated to the presence of ligatures. Neck ligatures remain a relatively safe, inexpensive, and informative method, but do present welfare concerns. Investigation into the efficacy of less-invasive alternatives such as videography should be conducted, especially when working with rare and declining species. We documented no mortality as a result of ligature placement, but researchers should minimize the time that ligatures are in place to reduce stress to both parents and nestlings.

\section{ACKNOWLEDGMENTS}

This research was conducted under University of Vermont Institutional Animal Care and Use Committee protocol 05-039. The project was supported by the National Research Initiative of the USDA Cooperative State Research, Education and Extension Service (grant number 03-35101-13817) and the Natural Resource Conservation Service's Wildlife Habitat Management Institute. Supplies and summer support to LPL were provided by the University of Vermont's Hughes Endeavor for Life Science Excellence (HELiX) program. Additional funding was provided by University of Vermont's College of Agriculture and Life Science. We thank Shelburne Farms and Sam Dixon, and the Ross and Thibault families for allowing us to conduct research on their property. Field assistance was provided by Thomas Lawrence, Stacey Thompson, Roger Masse, Christopher Lang, and Zachary Rowe. T. B. McFadden, R. C. Hovey, F.-Q. Zhao, and the Strong Graduate Laboratory provided support and comments on earlier versions of the manuscript.

\section{LITERATURE CITED}

Clotfelter, E. D., C. R. Chandler, V. Nolan JR., AND E. D. KetTerson. 2007. The influence of exogenous testosterone on the dynamics of nestling provisioning in Dark-eyed Juncos. Ethology 113: $18-25$.

Gaunt, A. S. And L. W. ORING. 1999. Guidelines to the use of wild birds in research. Second Edition. The Ornithological Council, Washington, D.C., USA.

Johnson, E. J., L. B. Best, And P. A. Heagy. 1980. Food sampling biases associated with the "ligature method". Condor 82:186-192.

Martin, P. A., D. L. Johnson, D. J. Forsyth, And B. D. HILL. 2000. Effects of two grasshopper control insecticides on food resources and reproductive success of two grassland songbirds. Environmental Toxicology and Chemistry 19:2987-2996.

Mellott, R. S. AND P. E. Woods. 1993. An improved ligature technique for dietary sampling in nestling birds. Journal of Field Ornithology 64:205-210.

ORIANS, G. H. 1966. Food of nestling Yellow-headed Blackbirds, Cariboo Parklands, British Columbia. Condor 68:321-337.

Perlut, N. G., A. M. Strong, T. M. Donovan, And 
N. J. BuCKLEY. 2006. Grassland songbirds in a dynamic management landscape: behavioral responses and management strategies. Ecological Applications 16:2235-2247.

Poulsen, J. G. AND N. J. AEbischer. 1995. Quantitative comparison of two methods of assessing diet of nestling Skylarks (Alauda arvensis). Auk 112: 1070-1073.

Robertson, R. J. 1973. Optimal niche space of the
Red-winged Blackbird. III. Growth rate and food of nestlings in marsh and upland habitat. Wilson Bulletin 85:209-222.

Rosenberg, K. V. And R. J. Cooper. 1990. Approaches to avian diet analysis. Studies in Avian Biology 13:80-90.

Shustack, D. P. 2004. Bobolink and Savannah Sparrow habitat selection in the Champlain Valley. Thesis. University of Vermont, Burlington, USA. 